(Aus der Universitäts-Hautklinik zu Breslau [Direktor: Geh. Med.-Rat Prof. Dr. Jadassohn].)

\title{
Eine Soormykose der Nägel bei einer Salvarsan-Dermatitis.
} (Reaktionen tierischer Immunseren mit Soorpilzen. Soorähnliche Pilze als Saprophyten auf pathologisch veränderter Haut.)

\author{
Von \\ Dr. Wilhelm Frei, \\ Assistent der Klinik.
}

Durch eine große Reihe von Beobachtungen ist es wahrscheinlich geworden, daß Pilze der Soorgruppe auf der Haut pathogene Wirkungen entfalten können.

So haben $\operatorname{Ibrahim}^{1}$ ) und $\mathrm{Beck}^{2}$ ) bei Säuglingen in den ersten Lebenswochen, die an Soor der Mundschleimhaut litten, Hantveränderungen gefunden, als deren Urheber sie die im erkrankten Gewebe angetroffenen Soorpilze ansahen.

Ferner wäre nach Kaufmann-Wolf ${ }^{3}$ ) auch eine von Jakobi ${ }^{4}$ ) beschriebene, bei Geistesgestörten, und zwar hauptsächlich bei kachektischen Individuen, nach längerem Aufenthalt im Dauerbade auftretende Hauterkrankung der Gruppe dieser Krankheiten zuzuzählen, da die Autorin annimmt, daß der in der veränderten Haut gefundene und von Küster ${ }^{5}$ ) genau untersuchte Pilz den Soorpilzen nahesteht.

Wenn Kaufmann-Wolf die Hypothese aufstellt, daß auch die Erreger der Pityriasis versicolor und des Erythrasma zur Soorpilzgruppe zu rechnen sind, so muß man wohl ihrer eigenen Anschauung beipflichten, daß diese Hypothese noch weiterer exakter Prüfung von botanischer Seite bedürfe.

Aber nicht nur bei solchen gewissermaßen soordisponierten Personen - Säuglingen und kachektischen Erwachsenen - hat man den Soorpilz in Krankheitsherden der Haut nachweisen können, sondern es sind in den letzten Jahren auch bei einer Gruppe von lokalisierten, einheitlich charakterisierbaren Hauterkrankungen erwachsener, in normalem Allgemeinzustand befindlicher Personen soorähnliche Pilze gefunden worden [Kaufmann-Wolf, Gougerot und Gancéa ${ }^{6}$ ), Hudélo und Montla $u r^{7}$ ), Muijs $\left.\left.{ }^{8}\right)\right]$.

Während bei den ersterwähnten Erkrankungen außer der allgemeinen Soordisposition auch noch spezielle eine Hautdisposition 
schaffende Momente - Maceration der Haut durch uringetränkte Windeln bzw. infolge des Dauerbades - gegeben waren, werden bei den letzteren auch 'über eine lokale, der Infektion vorangehende Hautschädigung bestimmte Angaben nicht gemacht; nur wird betont, daß die Ansiedelung der Soorpilze stets an, Stellen - wie den Interdigitalräumen oder der Inguinalgegend - erfolge, wo durch das Vorherrschen feuchter Wärme Gelegenheit zur Maceration gegeben wäre.

All die beschriebenen Krankheitsformen besitzen eine Reihe semeinsamer Merkmale, die schon kliniseh den Gedanken eines einheitlichen. Ursprungs nahelegt. Sie treten unter dem Einfluß - körperfremder oder körpereigener - Feuchtigkeit auf, zeigen Macerationserscheinungen, beschränken sich auf die oberen Schichten der Epidermis und haben Neigung zu flächenhafter Ausdehnung bzw. za Konfluenz von Einzelherden. Diese gemeinsamen Merkmale erinnern in manchem an das Krankheitsbild, das der Soorpilz auf den Schleimhäuten hervorruft, so daß die Annahme nicht unberechtigt erscheint, den einheitlichen Ursprung jener Hauterkrankungen in den soorähnlichen Pilzen zu erblicken, die bei allen Einzelbeobachtungen fast immer reichlich im erkrankten Gewebe zu finden waren, wenn man auch zugeben muß, daß im allgemeinen exakte Beweise für die ätiologische Bedeutung dieser Pilzo nicht erbracht worden sind und sich auch wohl nur schwer erbringen lassen.

Zu den gemeinsamen Merkmalen dieser Soormykosen der Haut rechnet Kaufmann-Wolf auch die Tatsache, daß sie niemals a uf Haare oder Nägel übergreifen. Ws kann natürlich nicht bestritten werden, daß bei den erwähnten Beobachtungen Nagelerkrankungen nicht beschrieben worden sind, aber es wird durch die folgenden Ausführungen doch erwiesen, da B a uch das Nagelgebiet dem Soorpilz zugänglich werden kann.

Ferner liegen bereits einige Mitteilungen über Soorerkrankungen der Nägel in der Literatur vor.

Gemeinsam ist den beobachteten Fällen ein überaus chronischer Verlauf unter Entartung und Deformierung der Nagelplatte sowie unter Entzündungsvorgängen in ihrer Umgebung, die nach längerem Bestehen der Erkrankung abzuklingen scheinen.

Forbes ${ }^{9}$ ) beschreibt eine bei einem $3^{1 / 2}$ jährigen. Mädchen seit $2^{1 / 2}$ Jahren bestehende Erkrankung der Fingernägel, die mit Entzündungserscheinungen in der Umgebung der Nägel begonnen und zu atrophischen sowie keratotischen Veränderungen an den Nagelplatten geführt hatte, und der eine mit Unterbrechungen fortdauernde Sooraffektion des Mundes vorangegangen war. In den tieferen Teilen der Nagelplatten wurden mitte]s Kulturverfahrens Soorpilze gefunden. Der 
Autor läßt dabei die Frage offen, ob diese Pilze die Nagelerkrankung hervorgerufen oder sich nur sekundär in den durch eine - kulturell nicht nachweisbare - Trichophytie geschädigten Nägeln angesiedelt hatten.

Ferner teilt Pellie $\mathrm{r}^{10}$ ) einen Fall mit, bei den seit etwa 25 Jahren an verschiedenen Zehen hyperkeratotische Veränderungen des Nảgelbettes sowie Trübungen und Verfärbungen der Nagelplatte bestanden. Die erkrankten Nägel fielen von selbst ab, bevor sie bis an den freien Rand des Nagelbettes herangewachsen waren. In dem erkrankten Gewebe wurde ein Pilz nachgewiesen, der von Guillemin als der Soorgruppe nahestehend bestimmt wurde.

Neuerdings hat $\mathrm{Kummer}{ }^{11}$ ) in der Wiener dermatologischen Gesellschaft eine Patientin vorgestellt, die seit 2 Jahren an einer mit Entzündung des Nagelbettes und Deformierung der Platte einhergehenden Nagelerkrankung litt, bei der gleichfalls Pilze der Soorgruppe gefunden wurden, und hat außerdem über 2 andere analoge Fälle berichtet.

Schließlich kann man auch unter den bisher mitgeteilten Fällen von Blasto* mykoseerkrankungen der Nägel [Dübendorfer ${ }^{12}$ ), Selene ${ }^{13}$ ), Bourgeois $\left.{ }^{14}\right)$ ] den von Dübendorfer im .Jahre 1904 aus der hiesigen Klinik beschriebenen Fall auf Grund der veröffentlichten histologischen, kulturellen und tierexperimentellen Untersuchungsbefunde mit einiger Wahrscheinlichkeit als Soormykose auffassen. Hier handelte es sich um eine seit über 2 Jahren bestehende Erkrankung zweier Fingernägel, die zu Veränderungen der Nagelsubstanz, zur Ansammlung eitriger, bröckeliger and faseriger Massen auf dem Nagelbett und zur Entzüindung des Nagelwalls geführt hatte.

Bei keinem der Fälle wird über eine vorangehende, dispositionschaffende Schädigungder Nägel berichtet, möglicherweise nur deshalb nicht, weil die Patienten erst mit der ausgebildeten, seit langem bestehenden Affektion zur Beobachtung kamen, und die anamnestischen Angaben nicht ausreichend waren.

Dagegen läßt sich für den von uns beobachteten Fall, bei dem sich die Mykose der Nägel erst während des Aufenthaltes in der Klinik entwickelte, feststellen, daßderInfektion neben einererheblichen Allgemeinschädigung des Organismus auch eine schwere lokale Schädigung des befallenen Nagelgebietes vorangegangen war.

Im einzelnen gestaltete sich das Krankheitsbild folgendermaßen:

\section{Krankengeschichte.}

Die 35jährige Putzmacherin Berta R., eine grazil gebaute, mittelgroße Frau, hatte wegen einer vor 2 Jahren erworbenen, seropositiven primären Lues vier kombinierte Salvarsan-Quecksilberkuren durchgemacht. Im AnschluB an die letzte Kur, bei der sie nicht wie bei den vorangegangenen Kuren Neo-Salvarsan sondern Salvarsan-Natrium erhalten hatte, erkrankte sie a n einer allge meine $\mathbf{n}$ Dermatitis und einer unter starker Schwellung auftretenden enanthemartigen Affektion der Mundschleimhaut, die ihre Aufnahme in die Klinik erforderlich machten (22. IX. 1918).

An den inneren Organen waren krankhafte Veränderungen nicht festzustellen. Das Blut enthielt im com 3,3 Millionen Erythrocyten und 8000 Leukocyten, darunter 1\% eosinophile. Der Urin war frei von Eiweiß und Zucker. Die Wassermannsche Reaktion negativ. 
Die Krankheitserscheinungen der Mundschleimhaut und Haut crwiesen sich als recht hartnäckig, begannen aber endlich nach etwa zweimonatlicher Behandlung unter starker Pigmentier ung der Haut am übrigen Körper zu weichen, während sie gleichzeitig auf den bisher verschont gebliebenen behaarten Kopf übergriffen.

Außerdem traten jetzt multiple Schweißdrüsenabscesse in beiden Achse]höhlen auf, die monatelang anhielten, wiederholte Incisionen erforderlich machten und die ohnehin schon schwer geschädigte Patientin noch weiter bis zu einem Mindestgewicht von $34^{1 / 2} \mathrm{~kg}$ herunterbrachten. Aus dem Absceßeiter wurde Staphylococcus pyogen. aureus in Reinkultur gezüchtet, während im Blut, das wegen des anhaltenden Fiebers wiederholt kulturell untersucht wurde, pathogene Keime nicht gefunden werden konnten. Es kam vorübergehend zu einer leichten Cystitis, die durch Bact. proteus - im Katheterurin reichlich als einziger Mikroorganismus nachgewiesen - hervorgerufen war.

Allmählich bildeten sich Hyperkeratosen aus teils in Form schwieliger Verdickungen an den Füßen, besonders an den Sohlen, teils in kleinwarziger Form an der Haut des Rumpfes unterhalb der Mamma.

Bedeutende Veränderungen hatten vor allem die Nägel erlitten. Die Fingernägel zeigten stark ausgeprägte Längsleisten und Querfurchen, die Platten erschienen im ganzen verdickt und bräunlich verfärbt, ihre Oberfläche stumpf und abgeschilfert, und unter ihrem freien Rande lagen starke keratotische Massen. Die Nägel der Zehen waren etwas weniger stark, aber immer noch recht erheblich verändert: die Platten teils im ganzen verdickt, teils trugen sie buckelförmige Erhebungen von Nagelsubstanz; unter dem freien Rande lagen gleichfalls verhornte Epithelmassen.

Am 19. I. 1919 wurde eine Auftreibung und grünlich-weißliche Verfärbung beider Kleinfingernägel in der Gegend der Lunula, begleitet von einer leichten Schwellung, Rötung und Druckschmerzhaftigkeit des Nagelwalls, festgestellt. Die Pat. gab an, dicse Erscheinung seit 3 Tagen zu bemerken, ohne daß sie vorher Rhagaden oder Eiterung aus dem Nagelfalz beobachtet hätte. In den nächsten Tagon nahm die Auftreibung der Nägel sowie die Entzündung ihrer Úmgebung zu. Gleichzeitig bildete sich dieselbe Affektion am rechten Daumen und linken Ringfinger aus. Am rechten Arm entwickelte sich eine Lymphangitis und eine diffuse Infiltration und Rötung der Haut der Ellenbeuge.

Darauf wurden die Nagelplatten beider kleiner Finger von der Wurzel aus, die nur lose im Falz saß, entfernt. Die Entfernung ging leicht ohne Blutung und Verletzung des Nagelbettes vor sich, so daß man den Eindruck hatte, daß die Nägel nicht weit von ihrer spontanen Ablösung gestanden hatten. Auf der Innenseite der Nagelplatten befanden sich an der Stelle, wo die grünlichweiße Verfärbung zu sehen gewesen war, geringe Mengen grünlich-weißen, bröckeligen Eiters, während weiter distalwärts keratotische Massen lagen. Auf dor Außenseite, besonders an den Querfurchen, war die Nagelsubstanz teilweise oberflächlich aufgesplittert. Das Nagelbett zeigte nur in der Gegend der Matrix, wo der Eiter gelegen hatte, oberflächliche Defekte.

Bei der mikroskopischen Unters uchung des Eiters, die nur an dem Nagel des linken Fingers vorgenommen wurde, wurden zahlreiche Mycelfäden und ganz vereinzelt Pilze in Hefeform sowie detritusartige Massen und einzelne polynucleäre Leukocyten gefunden. Auf diesen Befund hin wurden Kulturen angelegt, die außer einigen banalen Bakterien wie Staphylococcus albus und pseudodiphtherieartigen Stäbchen - der extrahierte Nagel war vor 
Feststellung des Pilzbefundes nicht steril aufbewahrt worden - zahlreiche hefeartige Kolonien ergaben.

Die Entzündungserscheinungen an den Endgliedern der kleinen Finger nahmen unter feuchten Verbänden schnell $a b$, auch die Rötung und Infiltration in dex rechten Ellenbeuge ging zurück, nachdem sie sich vorher noch distalwärts auf die Innenseite des Vorderarms ausgebreitet hatte. Am Oberarm blieb noch einigc Zeit ein derber Lymphstrang bestehen, ohne daß an der darüber gelegenen Haut Entzündungserscheinungen wahrzunehmen gewesen wären.

Nach einigen Tagen wurde auch der Nagel des rechten Daumens, wo die Entzündung weiter fortgeschritten war, unter allen aseptischen Kautelen entfernt. Die Platte war fester als an den Kleinfingernägeln mit dem Bett verbunden, so daß es zu leichten Defekten des Nagelbetts kam. Die unter der Nagelplatte gelegene Eitermenge war geringer und kompakter. Keratotische Ablagerungen waren gleichfalls vorhanden. Der freistehende Teil der Platte war nicht homogen, sondern bestand aus übereinandergeschichteten, verschieden weit reichenden Lamellen mit unregelmäßig zackiger Begrenzung. Im Eiter mikroskopisch der gleiche Befund wie zuvor, kulturell auf den verschiedensten Nährböden (Nähragar, Ascitesagar, Sabouraudscher Maltoseagar, Schüttelkulturen in hoher Schicht von Traubenzuckeragar) bei Brutschrank- wie bei Zimmertemperatur, Reinkultur eines hofeartigen Pilzes.

Nach einer Woche wurde schließlich auch der Nagel des linken Ring. fingers, an dem sich in der Gegend des Nageloberhäutchens eine kleine Fistel gebildet hatte, entfernt. Der Befund war im allgemeinen der gleiche wie bei den andern Nägeln, nur wurden im mikroskopischen Bild neben Mycelien auch zahlreiche Kokken und in den Kulturen neben hefeartigen Kolonien Staphylococcus albus und pseudodiphtherieartige Stïbchen gefunden. Der Defekt in der Gegend der Matrix, wo der Eiter gelegen hatte, war tiefer als bei den anderen Nägeh und reichte weit unter den Nagelwall herunter.

Die Entzündungserscheinungen an den Nagelgliedern gingen nach den Extraktionen unter feuchten und später unter Salbenverbänden gut zurück. Die zunächst nachwachsende Nagelsubstanz zeigte eine höckerige Oberfläche, die spätere hatte normales Aussehen.

Kurz darauf traten noch an der 3. und 4. Zehe des linken FuBes und später am Ringfinger der rechten Hand leichte Nagelentzündungen auf. Sie äußerten sich in einer" geringen Schwellung und Rötung des proximalen Teils des Nagelwalls, besonders an seinem medialen Winkel, und führten zur Bildung geringer Mengen trüben Exsudats, das bei Druck auf den proximalen Teil der Nagelplatte aus dem Nagelfalz hervordrang. In dem Exsudat wurden stets neben andern Keimen mikroskopisch Mycelfäden und kulturell Hefeformen nachgewiesen. Die Entzündungserscheinungen gingen unter feuchten Verbänden ohne Verlust der Nagelplatte zurück.

Kurz nach Beobachtung der ersten Nageleiterungen fiel bei Besichtigung des behaarten Kopfes ein intensiver Hefegeruch auf. Hier hatten die Entzündungserscheinungen stark zugenommen und hatten unter erheblichem Haarverlust zu einer diffusen Rötung und ödematösen Durchtränkung der Haut sowie zur Bildung zahlreicher stecknadelkopforoßer, z. T. konfluierender Pusteln geführt. Die Behandlung des Kopfes erwies sich als überaus schwierig, so daß vielfach zwischen feuchten Verbänden verschiedener Art, Salben und Zinköl, das noch am besten vertragen wurde, geweohselt werden mußte. Bei Anwendung der feuchten Verbände hatten sich schon einige Zeit vor der Nagelerkrankung unter Beteiligung des schlecht entfernbaren Zinkoxyds auf der Kopfhaut dichte, von Eiter unterschichtete Krusten ausgebildet. In 
diesen wurden nunmehr bei der vorgenommenen Untersuchung neben vielen anderen Keimen mikroskopisch ganz vereinzelte Mycelfäden und zahlreiche Hefeformen sowie kulturell befeartige Kolonien gefunden, während sich nach vorangegangener mechanischer Entfernung der Auflagerungen und Desinfektion der Oberfläche weder in Schuppen noch in Pusteln der Kopfhaut noch an herausgezogenen Haaren Pilze nachweisen ließen.

Außerdem wurde auch noch an zahlreichen Stellen des übrigen Kör pers nach Pilzen ges u cht: in der Mundhöhle, in der Vagina, in den Leistenbeugen, sowie an mehreren Hautbezirken, wo noch Überreste der Dermatitis bestanden. Nirgends wurden Pilze gefunden: ebensowenig in Hornlamellen der Fußsohle, in Geschabseln von der freien Oberfläche der Platte gesunder und kranker Nägel und im Nagelfalz nichtinfizierter Nägel. Auch Urin und Blut, erwiesen sich frei von Pilzen.

Die Entzündungserscheinungen auf dem behaarten Kopf hielten sich noch längere Zeit mit Schwankungen auf gleicher Höhe. Auch die Pilze waren noch etwa 7 Wochen hindurch nachzuweisen. Schließlich trat nach allmählicher mechanischer Entfernung der aufgelagerten Krusten unter Behandlung mit Borsäure. lösungen Besserung ein, der positive Pilzbefund hörte auf, die Entzündung verschwand, und die Haare begannen nachzuwachsen.

Da sich inzwischen auch die Infiltrate in den Achselhöhlen resorbiert hatten, konnte die Patientin am 6. VT. 1919 aus der Klinik als geheilt entlassen werden. Bei der Entlassung wiesen sämtliche Finger- und Zehennägel, sowohl die infizicrt gewesenen wio die andern, nur noch in der Nähe der freien Ränder geringe UnregelmäBigkeiten an der Oberfläche auf, während die nachgewachsene Nagelsubstanz normales Aussehen hatte. Die Hyperkeratosen unter den freien Nagelrändern, an Fußsohle und Rumpf waren verschwunden, dic Melanodermie nur noch geringgradig. Jie Kopfhaut war vollkommen reizlos, der Haarwuchs gleichmäBig dicht.

Ein Viertel- und ein Halbjahr nach der Entlassung stellte sich die Pat. wieder vor. Die Nägel waren gesund, das Kopfhatar stand wieder so dicht, wio es nach iher Angabe vor der Erkrankung gestanden hatte.

Zusammenfassend, läßt sich das Krankheitsbild folgendermaken. (harakterisieren:

Beieiner Patientinmitgoneralisicrter, nachkombinicrter Salvarsan-Quccksilberkur a ufgetretener Dermatitis, die zur Schwächung des ganzen Organismus und zu einer Reiho verschiedener Infektionen führte, bildeten sich auBer verschicdenen Zeichen der Arsenvergiftung keratotische Veränderungen, unter anderem an den Nägeln, aus. Im geschädigten Nagelgebiet entwickelten sich entzündliche zu Eiterabsonderung führende Prozesse, bei denen in allen untersuchten Nägeln Mycelfäden und Hefeformen, zum Teil in Reinkultur, gefunden wurden. Mikroorganismen von ähnlichem Aussehen konnten auch in krustösen Massen, die der stark entzündeten Kopfhat aufgelagert waren, nachgewiesen werden, während: sie am übrigen Körper, auch auf den Schleimhäuten, nicht konstatiert wurden. 


\section{Die pathogene Bedeutung der gefundenen Pilze.}

Die Frage, ob den gefundenen Pilzen eine pathogene Bedeutung zukommt, muß für ihre verschiedenen Ansiedelungsstätten in verschiedenem Sinne beantwortet werden.

Daß sie an den Entzündungsvorgängen auf dem behaarten Kopf einen wesentlichen Anteil hatten, ist nicht anzunehmen, da sie, wie bereits erwähnt, weder in der Oberflächenschicht der Kopfhaut noch in den Pusteln - die Staphylococcus aur. enthielten - noch an der Oberfläche oder im Innern, herausgezogener Haare, sondern nur in den Krusten, die der Kopfhaut auflagen, gefunden wurden.

Um ein Bild von der Zusammensetzung dieser Auflagerungen und der Menge der in ihnen vorhandenen Pilze zu gewinnen, wurden Teile von ihnen in Alkohol gehärtet, in Paraffin eingebettet und in Sagittalschnitten untersucht. Zur Darstellung der Pilze wurde nach $W$ aelsch, zu der der sonstigen Bestandteile mit Löf $\mathrm{fle}$ r schem Methylenblau gefärbt. Die Auflagerungen bestanden in ihrem äußeren Teil hauptsächlich aus Massen degenerierter Epithelien, zwischen denen polynucleäre Leukocythen und Züge anscheinend wohlerhaltener, z. T. parakeratotischer Hornlamellen lagen, und in ihrem inneren, der Kopfhaut zugekehrten Teil aus einer Schicht polynucleärer Leukocyten. In beiden Schichten, besonders in der äußeren, lagen große Massen teils grampositiver, teils gramnegativer Bakterien. Auch die Pilze - hauptsächlich Hefeformen, nur vereinzelt Mycelien - waren in großer Menge vorhanden und gleichfalls über sämtliche Schichten verteilt, bevorzugten aber ebenso wie die Bakterien die äußere Schjeht, wo sie sich besonders dicht, in langen Reihen angeordnet, in den Hornlamellen angesiedelt hatten.

Wenn auch den nur in abgestoßenen, macerierten Epidermismassen wuchernden Pilzen ein Anteil an den örtlichen Entzündungserscheinungen nicht zugesprochen werden kann, so hat diese Brutstätte doch möglicherweise insofern eine gewisse pathogene Bedeutung, als es nicht unwahrscheinlich ist, daß vonhieraus die Úbertragung der Pilze auf die Nägel stattgefunden hat.

Dafür, daß die Pilze an den Nägeln pathogene Wirkungen entfaltet haben, spricht in erster Peihe die Tatsache, daß sie sich hier im kranken Gewebe nachweisen lieBen.

Einer der exstirpierten Fingernägel, der Nagel des rechten Daumens, wurde nach Einbettung in Celloidin in Sagittalschnitten untersucht, die mit HämatoxylinEosin, Löflerschem Methylenblau sowie nach Gram in den Modifikationen von Weigert und Waelsch gefärbt wurden. Die Pilze wurden durch sämtliche Färbemethoden dargestellt, hoben sich aber am deutlichsten bei der Färbung nach Waelsch vom Gewebe ab, während sich zur Darstellung ihrer Struktur, soweit sie innerhalb schwach färbbaren Gewebes lagen, Löffler sches Methylenblau als besonders geeignet erwies.

Die Nagelplatte zeigte in ihrem distalen Ende bis über die mittleren Bezirke hinaus Aufsplitterungen, zwischen denen keratotische, z. T. polynucleäre Leukocyten enthaltende Massen lagen. Sie war in der Gegend der Wurzel auf ihrer 
Ober- und Unterseite von einem schmalen, vereinzelte Leukocyten tragenden Epithelsaum bekleidet, der auf der Unterseite distalwärts durch parakeratotisches, fact leukocytenfreies Gewebe abgelöst wurde. Dieses Gewebe zeigte z. T. eine circuläre, geschichtete, epithelperlenartige Anordnung, wie sie Heller ${ }^{15}$ ) bei ekzematösen Veränderungen der Nägel beschreibt, und wie sie nach Saboura ud ${ }^{16}$ ) auch bei Staphylokokkenerkrankungen der Nägel vorzukommen scheint.

Pilze waren sowohl in der Substanz der Nagelplatte wie in dem darunter gelegenen Gewebe nachzuweisen, während sie in dem der Platte aufliegenden Epithelsaum fehlten. Im allgemeinen traten sie in Form von Mycelfäden, die sich im Bereich der Platte durch besonderen Reichtum an Vakuolen auszeichneten, und nur ganz vereinzelt in Hefeform auf.

In der Nagelplatte fehlten die Pilze im proximalen sowie im distalen Abschnitt, ferner in den der freien Oberfläche zugekehrten Schichten und in den zwischen der aufgesplitterten Nagelsubstanz gelegenen keratotischen Massen. Sie waren hauptsächlich in dem dem Nagelbett aufliegenden unteren Drittel der Platte zu finden, wo sie in langen, zum großen Teil parallel der Oberfläche verlaufenden Zügen innerhalb der Hornlamellen lagen, die an diesen Stellen eine verstärkte Färbbarkeit und, wie man den Eindruck hatte, auch einen erhöhten Quellungsgrad aufwiesen.

In dem unterhalb der Platte gelegenen Gewebe fehlten die Pilze nur im Bereiche der Wurzel und waren in den weiter distalwärts gelegenen, aber noch zur Matrix gehörenden Epithelschichten sowie in dem parakeratotischen Gewebe nachzuweisen, wo sie besonders dicht in den Epithelperlen -- sowohl in den peripheren, circulären Sehichten wie in dem aus degenerierten Epithelien bestehenden Zentrum lagen. Mit vereinzelten, besonders langfädigen Exemplaren reichten sie bis in di $\boldsymbol{r}^{*}$ unter dem freien Nagelrand gelegenen keratotischen Massen hinein.

Andere Mikroorganismen als diese Pilze waren weder in dor Nagelplatte noch in dem ihr anhaftenden Gewebe aufzufinden.

Dieses Untersuchungsergebnis sprach dafü, daB die akute, entzündliche Erkrankung der Nägel durch die gefundenen Pilze hervorgerufen worden war.

Gegen die Annahme, daß die Pilze wie auf der Kopfhaut auch an den Nägeln nur als Saprophyten teils in abgestorbenen unter der Nagelplatte gelegenen keratotischen Massen teils in gleichfalls abgestorbenen vor ihrer spontanen. Ablösung befindlichen Platten gewuchert wären, sprach unter anderem, daß die ergriffencn Nagelplatten vor dem Auftreten der Entzündung nicht stärker verändert gewesen waren als die Platten der anderen Nägel, die keineswegs abstarben, sondern, ohne abzufallen, allmählich durch nachwachsende normale Nagelsubstanz ohne Kontinuitätstrennung verdrängt wurden.

Weiterhin muß man noch die Frage erörtern, ob nicht die a kuten Entzündungserscheinungendurch andere Mikroorganismen hervorgerufen sein konnten, und die Pilze nur im anderweitig infizierten Gewebe gewuchert waren. Hierauf wäre erstens zu erwidern, daß im Nagel des rechten Daumens außer diesen. Pilzen bei kultureller und histologischer Untersuchung keine anderen Mikroorganismen gefunden wurden. Wenn man dagegen noch 
einwenden könnte, daß die anderen Keime durch die nachträglich eingedrungenen Pilze schon hätten vernichtet sein können, wäre zweitens darauf hinzuweisen, da $\beta$ in sämtlichen 6 erkrankten Nägeln - 4 Finger- und 2 Zehennägeln -, die untersucht worden sind, stets Pilze zu finden waren, was wohl so einheitlich kaum der Fall gewesen wäre, wenn andere Keime die Entzündung verursacht hätten.

Es könnte auffallend erscheinen, daß eine Nagelmykose von so lebhaften Entzünd ungsvorgängen - Nagelbetteiterung und entzündliche Sehwellung des Nagelwalls - begleitet war. Doch haben auch die übrigen Autoren, von denen Nagelerkrankungen gleicher Art beschrieben worden sind, außer Pellier, dessen Patient aber die Affektion bereits seit 25 Jahren hatte, derartige Vorgänge beobachtet. Außerdem beweisen sie schon deswegen nichts für eine Mitbeteiligung von banalen Eitererregern, weil nach Sabouraud zum charakteristischen Bild der von Eitererregern - Staphylokokken erzeugten eigentlichen Onychien im allgemeinen gar kein akut entzündlicher sondern ein chronisch torpider Verlauf gehört.

Auf Grund dieser Auseinandersetzungen erscheint der Schluß berechtigt, daßdie Entzündung der Nägeldurchdiegefundenen Pilze hervorgerufen worden war.

Wenn man sich nun die Frage vorlegt, a uf welchem Wege die Pilze von der Kopfhaut in die Nägel hereingekommen sind, so kann man eine Einwanderung a uf dem Blutwege außer aus anderen Gründen schon wegen der geringen Allgemeinerscheinungen ausschließen. Demnach bleibt nur die Annahme übrig, daß die Einwanderung von der Oberfläche aus erfolgt ist, entweder auf direktem Wege, durch Berührung des Kopfes bzw. der abgelegten Verband,stoffe, oder, wie es wegen des Befallenseins von Zehennägeln nicht ganz unwahrscheinlich ist, auf indirektem. Wege, etwa durch Vermittlung des Badewassers, obwohl man auch annehmen könnte, daß sich vom Kopf aus zunächst die Fingernägel und von den Fingernägeln aus später die Zehennägel infiziert hätten.

Weiterhin wäre zu erörtern, welchen Weg die Pilze von der Oberfläche aus in das Innere des Nagels genommen haben. $\mathrm{Daß}$ sie nicht durch die Nagelplatte hindurch eingedrungen sind, kann man aus dem Fehlen der Pilze in der äußeren Schicht des histologisch untersuchten Nagels schließen. Dagegen gibt die histologische Untersuchung darüber keinen Aufschluß, ob die Infektion vom freien Rande oder vom Nagelfalz aus erfolgt ist. Doch kann man nach dem klinischen Bilde, wo sich besonders bei einigen weniger stark ergriffenen Nägeln -den, Zehennägeln und dem Nagel des rechten Ringfingers - die Entzündungserscheinungen auf den proximalsten Teil des Nagels be- 
schränkten, mit Wahrscheinlichkeit annehmen, daß die Infektion vo m proximalen Teil des Nagels aus erfolgt ist.

Es wäre nur noch zu besprechen, ob die lymphangitischen Veränderungen a m rechten Oberarm gleichfalls durch die in den Nägeln gefundenen Pilze oder durch Bakterien hervorger ufen waren. Fine bakterielle Infektion kann schon deswegen nicht ausgeschlossen werden, weil von den beiden zur Zeit des Auftretens der Lymphangitis erkrankten Nägeln der rechten Hand nur der Nagel des Daumens bakteriologisch untersucht worden war und sich als ausschließlich mit Pilzen infiziert erwiesen hatte, während eine bakteriologische Untersuchung des Kleinfingernagels nicht stattgefunden hatte, so daß für diesen. Nagel die Möglichkeit einer Mischinfektion bestand. Im Sinne einer bakteriellen Lymphangitis sprach sehrstarkda Ergebnis von biologischen Reaktionen, die mit dem Serum der Patientin und mit der Patientin selbst vorgenommen wurden.

Nach Widal, Abrami, Joltrain, Brissaud und Weilli.i) geben die Seren von Soorkranken - es wird weiter unten bewiesen werden, daß die hier gefundenen Pilze der Soorgruppe angehören eine schwache Agglutination mit Soorpilzen und eine stärkere mit Aufschwemmungen von Sporotrichosesporen. Wenn man auch nicht annehmen konnte, daß bei einer oberflächlichen, kurzfristigen Erkrankung, wie sie die beobachtete Nagelaffektion darstellte, die Bildung von Antikörpern hervorgerufen würde, so hätte man sie doch wohl bei einer Erkrankung der Lymphgefäße - und ebenso im Falle eines Eindringens der Pilze in die Blutbahn; s. oben - erwarten können.

Indessen verliefen alle Agglutinationsversuche, die mit den gefundenen Pilzen, ferner mit verschiedenen Soorpilzen sicherer Provenienz sowie mit Sporotrichosesporen nach den Vorschriften der Autoren angestellt wurden, in den Serumkonzentrationen von $1: 10$ bis $1: 160$ negativ. Auch die Komplementbindungsreaktion ergab mit verschiedenen nach der Vorschrift von Leuchs ${ }^{18}$ ) hergestellten Soorextrakten, unter anderem auch mit Extrakten der eigenen Stämme, ein negatives Resultat.

Ebenso verliefen Pirquetsche Reaktionen, zu denen dichte Aufschwemmungen durch Hitze abgetöteter Pilze - teils der aus dem Körper gezüchteten, teils erwiesener Soorstämme - verwandt wurden, bei der erkrankten Patientin nicht anders als bei einigen soorunverdächtigen Patientinnen.

Zusammenfassend läßt sich das Ergebnis der Betrachtungen dieses Abschnitts folgendermaßen formulieren:

Die beobachteten entzündlichen Nagelerkrankungen waren hervorgerufen durch die im erkrankten Gewebe 
gefundenen Pilze. Die Pilze sind wahrscheinlich von dex Kopfhaut aus übertragen worden, wo sie in großer Menge als Saprophyten in abgestoßenen, macerierten Epidermismassen wucherten. Die Ubertragung ist nicht anf dem Blutwege sondern von der Oberfläche her erfolgt, von wo aus die Pilze durch den proximalen Teil des Nagelfalz in den Nagel eingedrungen sind. Die die Nagelerkrankung begleitende Lymphangitis des rechten Armes war wahrscheinlich nicht mykotischen Ursprungs.

\section{Nähere Bestimmung der gefundenen Pilze.}

Wenn für die vorangegangenen Ausführungen die Voraussetzung bestanden hatte, daß die in den Nägeln und auf der Kopfhaut der Patientin gefundenen Pilze identisch seien, so bedurfte diese Voraussetzung besonders deswegen noch weiterer Beweise, weil die Pilze insofern gewisse Unterschiede untereinander aufwiesen, als sie auf der Kopfhaut in Hefe- und Mycelform, in den Nägeln dagegen fast ausschließlich in Mycel- und nur ganz vereinzelt in Hefeform aufgetreten waren. Aus diesem Grunde wurde eine Reihe von vergleichenden Untersuchungen mit Reinkulturen der vom Kopf und aus verschiedenen Nägeln gezüchteten Pilze angestellt.

Gleichzeitig handelte es sjch darum, eine Einordnung dieser Pjlze. ins System vorzunehmen.

Hierbei war schon durch das Resultat der direkten mikroskopischen Untersuchung insofern eine bestimmte Richtung gegeben, alș die vorhandenen Hefeformen a uf die Gruppeder Blastom yceten und die gleichzeitig in den Läsionen gefundenen Mycelien a uf die Untergruppe der soorähnlichen Pilze hinwiesen.

Immerhin waren zu einer exakten Bestimmung der Pilze noch weitere Untersuchungen erforderlich, $\mathrm{zu}$ denen vergleichsweise einige sichere Soorstämme herangezogen wurden, die teils aus der soorkranken Mundschleimhaut von Säuglingen selbst gezüchtet (bezeichnet als Stamm Kinderklinik A und B), teils aus der Sammlung des hiesigen Hygienischen Instituts bezogen waren (Stamm Hygienisches Institut I und II).

Die Untersuchungen erstreckten sich auf eine Reihe von kulturellen, mikroskopischen, tierexperimentellen und serologischen Methoden, die in den einschlägigen Kapiteln des Kolle-v. Wassermannschen

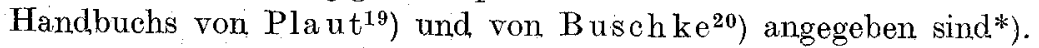

Alle diese Methoden zur Differenzierung der Pilze heranzuziehen,

*) Eine ausführliche Zusammenstellung. der Soorliteratur hat neuerdings

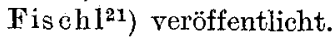


war deswegen erforderlich, weil sonst eine sichere Gruppierung wegen der vielfachen. Übergänge zwischen den einzelnen Glied,ern der Blastomycetengruppe nicht möglich gewesen wäre.

\section{A. Kulturelle Untersuchungen.}

Die Kulturen wurden tejls in Zimmer-, teils in Brutschranktemperatur $\left(37^{\circ}\right)$ gehalten. Das Wachstum sämtlicher Kulturen ging bei Brutschranktemperatur schneller vor sich, erreichte aber bei Zimmertemperatur - nur nach längerer Zeit - die gleiche Stärke. Sämtliche Stämme entwickelten, in der Kultur einen säuerlichen, hefeartigen. Geruch.

Gelatineplatten (10 proz. Nährgelatine): Bei den vom Kopf und, dem rechten, Daumennagel gezüchteten Stämmen die oberflächlichen Kolonien, porzellanweiß, gewölbt, schwach glänzend, rund, scharfrandig, bei mikroskopischer Betrachtung fein granuliert; die tiefen Kolonien leicht gelblich und rund. Ausläufer entwickelten sich während cinmonatiger Beobachtung nicht. Keine Verflüssigung.

Dasselbe Verhalten, bei den. Stämmen Kinderklinik A und B.

Bei dem Sammlungsstamm Hygienisches Institut I nach 10 Tagen Wachstum radiär gerichteter fädiger Ausläufer, die bei den oberflächlichen Kolonien kürzer und spärlicher als bei den tiefliegenden waren.

Gelatinestich (10 proz. Nährgelatine): Kulturen, von Stamm Kopf und von is aus verschiedenen Nägein gozüchteten Stämmen:

An der Oberfläche porzellanweißer, mattglänzender, flachgewölbter, glattrandiger Knopf, um den Stichkanal herum perlschnurartig aneinandergereihte, weißliche Kügelchen. Nach 19 Tagen in allen Kulturen rom stich ausgehende, feine baumartige Verzwejgungen. Keine Verflüssigung.

Bei Stamm Kinderklinik B dasselbe, nur traten die Verzweigungen etwas später auf; bei Stamm Kinderklinik A noch nach 2 Monaten keinerlei Verzweigungen.

Bei den Stämmen Hygienisches Institut I und II Wachstum an der Oberflüche flacher, matter, gefältelt, Rand gezackt. Vom Stichkanal aus bereits nach einer Woche Beginn der Verzweigung.

Agarstich $\left(37^{\circ}\right)$ : Ungefähr dasselbe Wachstum wie in Gelatine. Überall, auch bei Stamm Kinderklinik A, Verzweig ungen; bei den, Sammlungsstämmen am reichlichsten.

Maltose-Schrägagar $\left(37^{\circ}\right)$ : Wachstum mit bräunlicher Farbe, die je nach der Eigenfarbe des Agars verschieden intensiv ist; besonders intensiv bei Verwendung der braunen Pariser Maltose.

Bierwürzegelatine: Stichkulturen der Stämme vom Kopf, von, den Nägeln, Kinderklinik A und B, Hygienisches Institut I und II nach 5 Tagen verflüssigt. 
Plattenkulturen langsamer verflüssigt, besonders langsam die Sammlungsstämme.

Bierwürze (Zimmertemperatur): Überall etwa eine Woche lang Gasentwicklung. Flüssigkeit klar. Dicker, schleimiger Bodensatz. Bei den von der Patientin gezüchteten Stämmen keine Kahmhaut, dagegen bei den Sammlungsstämmen nach 12 tägigem Wachstum.

Bouillon $\left(37^{\circ}\right)$ : Bei sämtlichen Stämmen Flüssigkeit klar, feinflockiger Bodensatz.

Lackm usmolke-Merck (37 ${ }^{\circ}$ und Zimmertemperatur): Bei sämtlichen Stämmen Flüssigkeit klar, feinflockiger Bodensatz. Anfänglich geringe Rötung, später in schwache Blaufärbung umschlagend. Utberall Entwicklung sehr zarter, leicht zerreißbarer Oberflächenhäute.

Verhalten gegenüber verschiedener Zuckerarten: Zu den Untersuchungen wurden die Monosaccharide Dextrose, Laevulose, Galaktose und die Disaccharide Maltose, Saccharose, Lactose in Merckschen reinen Präparaten (,,purissim.") herangezogen.

Zur Untersuchung auf Säurebildung dienten bei Zimmer- und Brutschranktemperatur aufbewahrte, zuckerhaltige $(1 / 2 \%$ ), durch Azolitmin gefärbte Nährlösungen, wie sie von Reichenbach zur quantitativen Bestimmung der von Bakt. coli aus Milchzucker abgespaltenen Säure angegeben worden sind (S. Quantz 22).

Das Wachstum der Pilze war in diesen Lösungen nicht sehr üppig, aber auch nicht auffallend schwach.

Alle Stämme (vom Kopf, von sämtlichen untersuchten Nägeln, Stamm Kinderklinik A und B, Hygienisches Institut I und II) zersetzten Dextrose, Lävulose, Maltose und in ganz geringem Grade auch Galaktose unter Säurebildung; dagegen trat bei Saccharose und Lactose keine Änderung des Farbtons ein.

Zur Untersuchung auf Gasbildung wurden, zunächst Stich- und später Schüttelkulturen in Nähragar, dem $1 / 2 \%$ der verschiedenen Zuckerarten, zugesetzt war, angelegt.

Aber weder bei Brutschrank- noch bei Zimmertemperatur konnte eine Gasentwicklung festgestellt werden, auch nicht, als, um ein besseres Wachstum zu erzielen, statt des gewöhnlichen schwach alkalischen schwach saurer Agar verwandt wurde. Bei den Stichkulturen war das Wachstum an der Oberfläche und längs des Stichkanals allgemein bei denjenigen Zuckerarten, aus denen in der Nährlösung Säure abgespalten worden war, - auch bei Galaktose - stärker als in zuckerfreiem Agar; das Wachstum an der Oberfläche außerdem auch bei Saccharose, obwohl hier eine Zersetzung unter Säurebildung nicht nachgewiesen werden konnte.

Nunmehr wurden die Untersuchungen auf Gasentwicklung in 
flüssigen Nährböden (schwach alkalische Nährbouillon mit 1\% Zucker), die in Gürkölbchen gefüllt und, bei $37^{\circ}$ gehalten wurden, vorgenommen.

Sämtliche Stämme, die von der Patientin gezüchteten wie die vier sicheren Soorstämme, bildeten in geringer Menge Gas a us Dextrose, Lävulose und Maltose, dagegen kein Gas aus Galaktose, Saccharose und Lactose. Bei Dextrose trat die Gasbildung am schnellsten, bei Lävulose am langsamsten auf. Die einzelnen Stämme differierten im übrigen ein wenig in der Stärke der Gasentwicklung, aber die verschiedenen von der Patientin gezüchteten Stämme verhielten sich dabei ungefähr gleichartig.

Vergleicht man diese Resultate der kulturellen Untersuchungen mit den Angaben der Literatur über das Verhalten der Soorpilze, so kannmanimallgemeinen eine Übereinstimmung feststellen, einzig und allein fällt die Tatsache auf, daß in den Gelatineplatten die tiefliegenden Kolonien keine fädigen Ausläufer gebildet hatten, wie sie bei Soor beschrieben worden sind, und wie sie auch bei den Sammlungsstämmen aufgetreten waren. Indessen kann man dieser Differenz eine Bedeutung deswegen nicht beimessen, weil erstens einmal Verschiedenheiten im Aussehen echter Soorkolonien bekannt sind [Grasset ${ }^{23}$ ), Noisette $\left.{ }^{24}\right)$ ], weil zweitens die beiden von Soorkranken isolierten Pilze (Stamm Kinderklinik A und B) sich ebenso verhielten, und weil drittens das Wachstum der Pilzo in Gelatine- und Agarstichkulturen bewies, daß sie imstande waren, fädige Ausläufer in festen Nährböden zu bilden.

Das Verhalten der Pilze den verschiedenen $Z$ uckerarten gegenüber entsprach vollkommen den Angaben, die Fischer

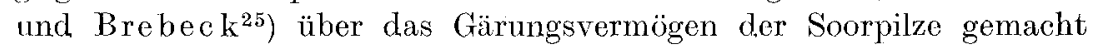
haben. Nur über das Verhalten der Soorpilze zur Galaktose, wo eine schwache Zersetzung unter Säure- und ohne Gasbildung festgestellt wurde, scheinen Beobachtungen bisher nicht vorzuliegen. Wenn sich in den festen Nährböden, die zur Prüfung der Gasabspaltung aus Zucker im allgemeinen weniger bei Pilzuntersuchungen als in der bakteriologischen Technik Verwendung finden, eine durch Risse im Nährsubstrat kenntliche Gasentwicklung nicht nachweisen ließ, so lag das wahrscheinlich an ihrer geringen Intensität, die eino Diffusion des gebildeten Gases ohne Verletzung des Nährbodens gestattete.

\section{B. Mikroskopische Untersuchungen.}

Über das Aussehen der Pilze in den Nägeln und den Auflagerungen auf der Kopfhaut ist weiter oben schon Näheres berichtet worden. Es sei hier nur noch nachgetragen, daß sie - wenn auch nicht in allen Exemplaren gleichmäßig stark - nach Gram färbbar waren, daß sich in den Mycelien durch Scharlach R Fett in 
feinsten Tröpfchen und größeren Tropfen sowie durch Jod Glykogen darstellen ließ, und daß die Mycelien in einzelnen Nägeln, wo eine Mischinfektion vorlag, gelegentlich Verzweigungen und, Chlamydospor'en aufwiesen. Vorweggenommen sei, da B a uch in den experimentell an Tieren gesetzten Läsionen die Pilze zum überwiegenden Teil in Mycel- und nur zum kleinen Teil in Hefeform auftraten.

Im Gegensatz hierzu überwogen in de $\mathrm{K}$ Kult ure $n$ im allge meinen die Hefeformen, besonders auf der Oberfläche fester Nährböden, wo nur ganz vereinzelt einmal ein Mycelfaden zu sehen war.

Die Hefezellen waren etwa $4-5 \mu$ lang und $4 \mu$ breit, hatten also zu einem Teil - der vorherrschend war - eine schwach ovale, zum andern Teil eine runde Form; vereinzelt kamen auch mehr in die Länge gezogene, schlauchförmige Zellen vor.

Das gleiche mikroskopische Bild boten auch die beiden Kulturen, die von soorkranken Säuglingen gewonnen waren, während bei den beiden Sammlungsstämmen die längeren Formen häufiger waren, und auch eine größere Neigung zur Mycelbildung bestand.

Die größeren Hefezellen hatten eine doppelt konturierte Membran und zeigten im Innern das große, von den meisten Autoren als Kern gedeutete Gebilde. Sie waren in Präparaten, die mit Löflerschem Methylenblau gefärbt waren, vielfach umgeben von einer metachromatisch gefärbten Schicht, die an Stellen, wo mehrere Zellen in Haufenform aneinanderhafteten, teilweise eine größere Mächtigkeit zu besitzen schien.

Die Zahl der Mycelfäden war bei allen Stämmen je nach der Zusammensetzung des Nährbodens und je nach dem Alter der Kultur verschieden. Besonders zahlreich traten sie in Lackmusmolke auf, wo sie schon nach 36 stündiger Bebrütung etwa ebenso stark wie die Hefeformen vertreten waren.

Sie besaßen im allgemeinen eine doppelt konturierte Membran, die nur an älteren degenerierten Exemplaren mitunter zu fehlen schien. Zum größten Teil waren sie septiert, nur bei wenigen, vor allem bei besonders langfädigen Formen, war eine Septierung nicht wahrzunehmen. Sie enthielten je nach dem Alter der Kultur verschieden zahlreiche Vakuolen und Granula, die sich teilweise intensiv metachromatisch färbten.

Chlamydosporen wurden von sämtlichen Stämmen, sowohl von den sicheren Soorstämmen wie vor allem von den bei der Patientin gezüchteten Stämmen, gebildet. Sie traten besonders zahlreich in alten Bierwürzekulturen auf und, saßen meist am Ende von Mycelfäden oder von Verzweigungen, diè von diesen ausgingen, selten an der Seitenwand oder im Verlauf der Fäden; teilweise lagen sie auch frei. Ihr 
Aussehen, entsprach ganz den Beschreibungen, die Linossier und. $\operatorname{Roux}^{26}$ ) von ihnen gegeben hatten: große, kugelförmige, von einer dichtèn Hülle umgebene Gebilde, die im Innern zahlreiche kleine Körnchen enthielten oder gröbere, kranzförmig um einen großen Innenkörper angeordnete Körner oder auch diesen Innenkörper allein.

Endosporen, wie sie Fischer und Brebeck oder Vuillemin ${ }^{27}$ ) beschrieben haben, konnten weder bei den sicheren Soorstämmen noch in den zu identifizierenden Kulturen, nachgewiesen werden. Auch durch Züchtung auf Gipsblöckchen bei $25^{\circ} \mathrm{C}$, die teils in Nährlösungen [Vorschrift von Buschke], teils in sterilem Wasser [Vorschrift nach Heim $\left.{ }^{28}\right)$ ] gehalten und teils mit jungen, teils mit alten Kulturen (Heim) beschickt wurden, wurde Sporenbildung nicht hervorgerufen. Die Untersuchung auf Sporen wurde im hängenden Tropfen und mittels der Möllerschen Sporenfärbung vorgenommen.

Auch Plaut hat die Angaben über Sporenbildung bei Soorpilzen, wie sie einerseits von Fischer und Brebeck andererseits von $V u i l-$ le min gemacht wurden, an seinen Stämmen nicht bestätigen können.

Somit entsprachen auch die mikroskopischen Beobachtungen an den bei der Patientin gezüchteten Stämmen durchweg den Befunden, wie man sie bei Soorpilzen zu erhalten pflegt.

\section{c. Tierversuehe.}

Die Tierversuche, die sämtlich mit Kulturmaterial vorgenommen wurden, erstreckten sich nach zwei Richtungen: Erstens wurde eine Reihe subcutaner, intraperitonealer und intravenöser Injektionen ausgeführt, und zweitens wurde versucht, a uf tierischen Schleimhäuten experimentell Soorplaques hervorzurufen.

Vergleichsweise wurden zu den meisten Versuchen neben den Stämmen der Patientin die sicheren Soorstämme herangezogen.

Zu den Injektionsversuchen wurden weiße Mäuse, Mecrsehweinchen und Kaninchen verwandt.

Injektionsversuche mit weißen Mäusen.

Infektion mit je 1/5 Normalöse 24stündiger Agarkultur.

\begin{tabular}{|c|c|c|c|}
\hline Stamm & Intravenös (Schwanzvene) & Subcutan & intraperitoneal \\
\hline Kopf & $\begin{array}{l}\text { + nach } 30 \text { Stunden. } \\
\text { Milz groß, sonst Sek- } \\
\text { tion o. B. Kulturell } \\
\text { aus Herzblut u. Milz } \\
\text { Pilze. }\end{array}$ & $\begin{array}{l}\text { Vorübergehende Infil- } \\
\text { tration der Impfstelle. } \\
\text { Lebt nach } 3 \text { Monaten. }\end{array}$ & Lebt nach 3 Monaten. \\
\hline Daumen & $\begin{array}{l}\text { + nach } 18 \text { Stunden. } \\
\text { Sonst dasselbe wie } \\
\text { bei Kopf. }\end{array}$ & $\begin{array}{l}\text { Vorübergehende Infil- } \\
\text { tration der Impfstelle. } \\
+ \text { nach } 40 \text { Tagen, } \\
\text { Sektion o. B. }\end{array}$ & Lebt nach 3 Monaten. \\
\hline
\end{tabular}


Injektionsversuche mit weißen Mäusen (Fortsetzung).

\begin{tabular}{|c|c|c|c|}
\hline Stamm & Intravenös (Schwanzvene) & Subcutari & Imtraperitoneal \\
\hline 4. Zehe & $\begin{array}{l}\text { + nach } 30 \text { Stunden. } \\
\text { Dasselbe wie b. Kopf. }\end{array}$ & Dasselbe wie bei Kopf. & $\begin{array}{l}\text { + nach } 8 \text { Tagen. Ab- } \\
\text { scesse in den Nieren. }\end{array}$ \\
\hline $\begin{array}{l}\text { Kinder- } \\
\text { klinik A }\end{array}$ & $\begin{array}{l}+ \text { nach } 18 \text { Stunden. } \\
\text { Sonst dasselbe wie } \\
\text { bei Kopf. }\end{array}$ & $\begin{array}{l}\text { Vorübergehende Infil- } \\
\text { trationder Impfstelle. } \\
\text { + nach } 35 \text { Tagen. } \\
\text { Angefault. }\end{array}$ & $\begin{array}{l}\text { + nach } 2 \text { Monaten, } \\
\text { Darmkatarrh. Sonst } \\
\text { Sektion o. B. Kultu- } \\
\text { rell o. B. }\end{array}$ \\
\hline $\begin{array}{l}\text { Hygien. } \\
\text { Inst. I. }\end{array}$ & $\begin{array}{l}\text { + nach } 18 \text { Stunden. } \\
\text { Sonst dasselbe wie } \\
\text { bei Kopf. }\end{array}$ & $\begin{array}{l}\text { Schwaches Infiltrat d. } \\
\text { Impfstelle. + nach } \\
\text { 35 Tagen. Angefault. }\end{array}$ & $\begin{array}{l}+ \text { nach } 3 \text { Monaten. } \\
\text { Sektion .o. B. }\end{array}$ \\
\hline
\end{tabular}

Injektionsversuche mit Meerschweinchen.

Infektion mit je $1 / 2$ Normalöse 24stündiger Agarkultur.

\begin{tabular}{|c|c|c|}
\hline Stamm & Subcutan & intraperitoneal \\
\hline Kopf & $\begin{array}{l}\text { Infiltration, zur Erweichung, aber } \\
\text { nicht zur Perforation führend. } \\
\text { Nach } 4 \text { Monaten lebend. }\end{array}$ & Lebt nach 4 Monaten. \\
\hline Daumen & Dasselbe. & Dasselbe. \\
\hline 4. Zehe & Dasselbe. & $\begin{array}{l}+ \text { nach } 2 \text { Monaten. Dünndarm- } \\
\text { katiarrh, sonst Sektion o. B. Kul } \\
\text { turell keine Pilze. }\end{array}$ \\
\hline klinik A & Dasselbe. & Lebt nach 4 Monaten. \\
\hline $\begin{array}{l}\text { Hygien. } \\
\text { Inst. I. }\end{array}$ & $\begin{array}{l}\text { Infiltrat geringer, bereits nach } \\
12 \text { Tagen resorbiert. Nach } 4 \text { Mo- } \\
\text { naten lebend. }\end{array}$ & Dasselbe. \\
\hline
\end{tabular}

Injektionsversuche mit Kaninchen.

Die Injektionsversuche wurden mit den Stämmen Kopf, Daumen, Kinderklinik A und Hygienisches Institut I zwecks Herstellung von Immunseren vorgenommen. Hierzu wurden lebende Pilze verwand. $t$, weil es nicht gelingt, durch abgetötete Soorkulturen Immunität zu erzeugen (Pla u t); und zwar wurde alle 5 Tage eine Viertelnormalöse 24stündiger Agarkultur intravenös gegeben. Diese Dosis erwies sich teilweise als zu hoch.

Die Kaninchen „Kopf“ und „Daumen“ gingen bereits am 4. bzw. 5. Tage nach der ersten Injektion ein.

Die Nieren der Tiere waren etwa auf das 3 fache der normalen Größe angeschwollen, ihre Rindensubstanz mit einer Unzahl hirsekornbis stecknađelkopfgroßer Absceßchen durchsetzt, während an der Marksubstanz mit bloßem Auge Veränderungen nicht wahrnehmbar waren. Außerdem wurden an verschiedenen Stellen des Magendarmkanals - in der Wand des Magens, verschiedener Dünndarmteile und des Blinddarms - Absceßchen gefunden, ebenso bei einem der 
beiden Tiere auch vereinzelte Herde in der Herzmuskulatur, während bei dem andern eine nähere Untersuchung des Herzens nicht stattgefunden hatte.

Bei mikroskopischer Untersuchung von Schnittpräparaten der Nieren sah man in den Absceßchen degenerierte Epithelzellen, Leukocyten, Lymphocyten, eine große Menge von Detritus und zahlreiche Pilze - meist in Mycelform --, die besonders dicht an der Peripherie der Herde lagen. Außerdem fanden sich auch zahlreiche Pilzansammlungen in Glomerulis und Harnkanälchen ohne ent. zündliche Reaktion. Vereinzelt waren derartige Pilzkonglomerate auch in der Marksubstanz anzutreffen.

Das mit Stamm Kinderklinik A geimpfte Tier starb 7 Tage nach der 3. intravenösen Injektion. Bei der Sektion konnte ein charakteristischer Befund nicht erhoben werden.

Das 4. Tier, mit dem Sammlungsstamm Hygienisches Institut I geimpft, überstand, ohne sichtliche Schädigung 4 intravenöse Injektionen, nach denen, weitere Impfungen nicht mehr vorgenommen wurden.

\section{Ưbertragung der Pilze a uf Schleimhäute.}

Von der Erfahrungstatsache ausgehend, daß eine Infektion der Schleimhäute mit Soor fast nur bei geschädigten Tieren gelingt, wurde zunächst versucht, bei einer Reihe von 6 ausgewachsenen Meerschweinchen, die an fortgeschrittener Impftuberkulose litten, auf der Mundschleimhaut Soorplaques durch Impfung mit Kulturmaterial zu erzeugen. Je 2 Tiere wurden mit Stamm Kopf, Daumen and Kinderklinik A geimpft. Die Impfung wurde mit eincm Gemisch von 24stündiger und 12tägiger Agarkultur, das intensiv auf die Schleimhaut eingerieben. wurde, vorgenommen. Bei der Hälfte der Tiere wurden vorher auf der Schleimhaut oberflächliche Verletzungen gesetzt. Bei keinem der Tiere bildeten sich Soorplaques aus.

Ferner wurden cin a usgewachsenes, nach einer abgeheilten Impfsyphilis mit großen, toxisch. wirkenden Dosen Silbersalvarsan behandeltes und dadurch schwer geschädigtes Kaninchen sowie zwei 6 Wochenalte, durch vorangegangenes Hungern bereits geschädigte und weiterhin fast ohne Nahrung belassene Kaninchen mit Agarkulturen der von, Kopf und Daumen gezüchteten Stämme stomachal und die beiden jungen Tiere zugleich vaginal nach vorheriger Bearbeitung der Schleimhäute mit dem scharfen, Löffel geimpft.

Bei dem einen der jungen Tiere wurde 4 Tage nach der Impfung a uf der Vaginalschleimhaut eine kleine, weiße, krümelige Auflagerung festgestellt, die aus Epithelien, Leukocyten, zahlreichen Hefezellen sowie einigen Mycelien bestand, bei dem andern 5 Tage nach der Impfung auf der $Z$ unge eine stecknadelkopfgroße, leicht abstreifbare, weiße Auflage- 
rung, die Epithelien, zahlreiche Bakterien und eine erhebliche Menge von Mycelien sowie einige Sproßformen enthielt. Beidemausgewachsenen Tier wurde nichts Soorverdächtiges gefunden.

Endlich wurden noch drei ausgewachsene hungernde $\mathbf{K a}$ ninchen nach dem von Stoos (zit. nach Plaut) angegebenen Verfahren vaginal nach vorangegangener Reizung der Schleimhaut mit den Stämmen Kopf, Daumen und Kinderklinik A und gleichzeitig mit frisch gezüchteter Staphylokokkenkultur geimpft. Es entwickelte sich ein kurzdauernder, eitriger Scheidenkatarrh, zur Bildung von Soorplaques kam es aber nicht.

Wenn man die Ergebnisse dieser Tierversuche überblickt, so kann man zunächst feststellen, da $B$ die Resultate der Injektionsversuche den Angaben entsprechen, die über das Verhalten der Soorpilze im Tierexperiment gemacht worden sind.

Betont wird stets die starke Wirkung der intravenösen Injektionen. Sie haben in den vorliegenden Versuchen bei Mäusen ausnahmslos in kurzer Zeit zum Tode geführt, und auch von den intravenös geimpften Kaninchen hat nur das mit dem alten Laboratoriumsstamm behandelte die Einspritzungen vertragen. Das Sektionsbild der beiden mit den Stämmen Kopf und Daumen geimpften Tiere war typisch für eine Soormykose der Kaninehen: die starke Beteiligung der Nieren mit Bevorzugung der Rindensubstanz und die Absceßbildung in der Magen- und Darmwand sowie in der Herzmuskulatur.

Bei subcutanen Injektionen werden nichtperforierende $\mathrm{Ab}$ scesse, wie sie gleichfalls hier zur Beobachtung kamen, beschrieben, an die sich gelegentlich eine tötliche Erkrankung anschließen kann (s. Mäuseversuche).

Peritoneale Einverleibung ist meist wirkungslos (s. Meerschweinehenversuche), nur Mäuse sind empfänglich (s. diese Versuche).

Der Tod der geimpften Tiere kann auch ohne multiple Abscesse in den inneren Organen, also durch Giftwirkung eintreten, wie es bei den vorliegenden Versuchen öfters beobachtet wurde.

Nicht ganz so überzeugend, sind die Versuche verlaufen, die darauf ausgingen, eine Soorerkrankung auf Schleimhäuten hervorzurufen. Es ist wahrscheinlich, aber nicht ganz sicher, daß sich bei den beiden jungen Kaninchen das eine Mal auf der Vaginal-, das andere Mal a uf der Zungenschleimhaut Soorplaques gebildet hatten; wahrscheinlich deswegen, weil Entwicklungsvorgänge an den Pilzen - bestehend in der Ausbildung von Mycelfäden, die in den aufgetragenen Agarkulturen kaum vorhanden gewesen waren - beobachtet werden konnten, weil ferner normalerweise die auf tierische Schleimhäute gebrachten Pilze schon nach 24 Stunden nicht 
mehr nachweisbar sein sollen (Plaut), und, weil endlich die weißlichen Auflagerungen erst nach mehrtägiger Inkubation entstanden sind; nicht ganz sicher aber deswegen, weil sich auch bei dem experimentell entstandenen Soor fest anhaftende Beläge bilden sollen, während die gefundenen Beläge nur lose der Schleimhaut auflagen.

Im übrigen ist bekannt, da $\beta$ auch bei Verwendung sicherer Soorpilze die experimentelle Erzeugung von Schleimhauterkrankungen. häufig auf Schwierigkeiten stößt, ebenso wie auch mit dem sicheren Soorstamm Kinderklinik A eine Infektion nicht gelungen ist. Möglicherweise hätten sich bei anderer Auswahl des Tiermaterials überzeugendere Resultate ergeben, doch standen zur Zeit weder Hühner und Tauben zur Kropfimpfung noch in den ersten Lebenstagen befindliche Säugetiere zur Verfügung.

\section{Serologische Untersuchungen.}

Wegen der Unsicherheit, die bei Versuchen, auf tierischen Schleimhäuten Sooraffektionen zu erzielen, besteht, und wegen des Fehlens anderer für den Soorpilz absolut charakteristischer Reaktionen kommt nach Pla ut bei der Identifizierung soorverdächtiger Pilze besonderer Wert den serologischen Untersuchungsmethoden zu.

Leider sind, diese Methoden bisher recht unzureichend ausgebaut. Eingehende Untersuchungen liegen nur über die Immunreaktionen soorkranker Menschen in der bereits oben besprochenen Arbeit von Widal, Abrami, Joltrain, Brissaud und Weill vor, während, über dic künstliche Erzeugung von Immunseren durch Tierimpfung außer einigen wenig umfassenden Beobachtungen von Roger und Noisette, die noch aus der Zeit der Entdeckung der Agglutinationsprobe stammen, nichts bekannt ist.

Roger ${ }^{29}$ ) hat festgestellt, daß man durch vorsichtig steigende intravenöse Injektionen von lebenden Soorpilzen Kaninchen gegen das Doppelte bis Dreifache der tödlichen Dosis schützen kann. Sät man in das Blutserum solcher Tiere Soorpilze cin, so tritt innerhalb 10-15 Minuten eine erhebliche Q uellung ihrer Membran und eine Agglutination a uf, Erscheinungen, die bei Verwendung von Normalseren ausbleiben. Iäßt man dic Pilze im Immunserum zur Entwicklung kommen, so findet man nach 24 Stunden - im Gegensatz zu dem üppi gen Wachstum im Normalserum - am Boden des Glases nur ein unbedentendes Häufchen kleiner, aus agglutinierten Pilzen mit mächtig gequollener Membran bestehender Körnchen, die in den nächsten Tagen noch etwas größer werden, die aber, nach 4-5 Tagen in neues Immunserum (!) übertragen, nicht mehr zur Entwicklung kommen.

Noisette, ein Schüler Rogers, hat eine Reihe von Kaninchen je einmal mit größerer Menge lebender Socrpilze verschiedener Herkunft intravenös geimpft und hat die Tiere - anscheinend stets, sicherlich in einigen Fällen - kurze Zeit, 18-48 Stunden, nach der Impfung getötet. In Serumproben dieser Tiere säte er 8 verschiedene Soorstämme ein und beobachtete mehrese Tage hindurch deren Wachstum. Er konnte meist eine geringere Entwicklung als im Normal- 
serum, Auftreten von Degenerationserscheinungen, Quellung der Membran und Klümpchen- oder Körnchenbildung (Agglutination) feststellen. Die Veränderungen betrafen stets den zur Impfung benutzten Stamm, häufig auch einen oder gelegentlich auch mehrere der anderen Soorstämme.

Mit Serumverdünnungen hatten Roger und Noisette bei ihren Versuchen noch nicht gearbeitet.

$\mathrm{Zu}$ den vorliegenden Versuchen, auf serologischem Wege die gefundenen Pilze als Soorpilze zu identifizieren, wurden, da Seren soorkranker Menschen nicht zur Verfügung standen und auch nur einen. sehr niedrigen Agglutinationstiter geben sollen, Seren von Kaninchen, diemit mehrfachen intravenösen Injektionen lebender Pilze behandelt waren, verwandt.

Ursprünglich war geplant, einerseits Seren gegen die von Kopf und Nägeln der Patientin gezüchteten: Stämme herzustellen und deren Reaktion sicheren Soorstämmen gegenüber zu prüfen, andererseits mittels sicherer Soorstämme Seren zu gewinnen und ihr Verhalten, gegenüber jenen Pilzen zu untersuchen. Wie bereits oben besprochen, gingen aber die Tiere, die mit Stamm Kopf und Daumen geimpft wurden, bereits wenige Tage nach der ersten Injektion an einer allgemeinen. Mykose zugrunde, so daß zu den serologischen Untersuchungen nur die beiden mit den Soorstämmen Kinderklinik A und Hygienisches Institut I behandelten Tiere übrigblieben. Das erste dieser beiden Tiere verendete 4 Tage nach der 3. Injektion (s. oben), nachdem ihm einen Tag zuvor noch eine geringe, aber zu einer Reihe von Agglutinationsversuchen ausreichende Menge Blut abgenommen worden war. Gleichzeitig wurde auch dem mit Stamm Hygienisches Institut I behandelten Tier Blut entnommen - und ebenso 2 Normaltieren für Kontrollreaktionen, - so daB die folgenden Untersuchungsreihen von Tieren stammten, die 6 Tage nach der 3. intravenösen Injektion standen. Das Serum des überlebenden Tiers wurde noch einmal 6 Tage nach der 4. Injektion - auf sein Agglutinationsvermögen dem eigenen Stamm gegenüber geprüft und, gab dabei denselben Titer wie zuvor.

\section{Agglutination.}

$\mathrm{Zu}$ den Agglutinationsversuchen wurden 24stündige Schrägagarkulturen benutzt, von denen eine Normalöse in $2 \mathrm{~cm} 0,85$ proz. Kochsalzlösung aufgeschwemmt wurde.

Die Versuche wurden nach der mikroskopischen Methode ausgeführt, da bei makroskopischer Betrachtung eine feine Körnelung störte, die bei den Aufschwemmungen aller benutzten Kulturen zu sehen war, obwohl hier die Pilze z u größten Teil einzeln und zum kleinen Teil auch nur in Häufchen von $2-3$ und nur ganz ausnahmsweise von 5-6 Exemplaren lagen.

Die Agglutinationsproben wurden nach ein- und zweistündigem Aufenthalt im Brutschrank sowie nach weiterer 16stündiger Lagerung bei Zimmertemperatur 
untersucht. Die Agglutination war bereits nach einer Stunde eingetreten, hatte aber ihren Höhepunkt erst nach 2 Stunden erreicht, während nach 18 Stunden eine wesentliche Verstärkung nicht mehr festzustellen war. Daher ist in der folgenden Übersichtstabelle der nach 2 stündigem Aufenthalt im Brutschrank beobachtete Titer angegeben worden.

Als positiv wurden diejenigen Proben betrachtet, bei denen im Gegensatz zur Kochsalzkontrolle (s. oben) einzeln liegende Pilze nur noch in bedeutender Minderzahl zu finden waren, und bei denen sich Häufchen von 10-60 Exemplaren gebildet hatten, und zwar wurden je nach der Menge der einzeln liegenden Zellen und der Größe der Häufchen 3 Stärkegrade in der Tabelle mit ++ , mit + und $(+)$ bezeichnet - unterschieden.

Gleichzeitig mit den Immunseren wurden zur Kontrolle zwei Nor malseren angesetzt, von denen das eine nur in der Verdünnung $1: 10$ eine schwache Agglutination $=(+)$ ergab, während das andere auch hier schon negativ reagierte.

Bei Untersuchung mit der Immersion zeigten die agglutinierten Pilze unverändertes Aussehen, insbesondere war eine Quellung der Membran nicht festzustellen, nur hatten sie ihre molekulare Beweglichkeit eingebüßt.

Ergebnis der Agglutinationsversuche.

\begin{tabular}{|c|c|c|c|c|c|c|c|c|c|c|}
\hline \multirow{2}{*}{ Stamm } & \multicolumn{5}{|c|}{ Serum Kinderklinik A } & \multicolumn{5}{|c|}{ Serum Hygienisches Institut I } \\
\hline & $1: 10$ & $1: 20$ & $1: 40$ & $1: 80$ & $1: 160$ & $1: 10$ & $1: 20$ & $1: 40$ & $1: 80$ & $1: 160$ \\
\hline lini & & -+ & $+t^{-}$ & + & - & + & & + & - & - \\
\hline n. Inst. & + & + & + & - & - & ++ & ++ & +1 & + & $\ldots$ \\
\hline Ko & 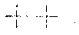 & + & $+\cdots$ & $(++)$ & - & + & $+-t$ & ++ & $\ldots$ & - \\
\hline nen & $t+$ & + & $i$ & $(+)$ & - & + & $\div-$ & + & 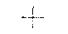 & - \\
\hline erklinik $\mathbf{B}$ & + & . t. & $(+)$ & -- & -- & & & & - & - \\
\hline Hygien. Inst. II & $(+-)$ & $\ldots$ & - & -.- & $\cdots$ & - & $\cdots$ & $\ldots$ & - & -. \\
\hline $\left.\mathrm{E}^{*}\right)$ & $\therefore$ &. & - & $\ldots$ & - & $\cdots$ & -- & - & -- & $\cdots$ \\
\hline Saccharomyc.Leou, $\left.{ }^{* *}\right)$ & $\cdots$ & $\ldots$ & $\cdots$ & -- & - & - & & & - & - . \\
\hline
\end{tabular}

Die vorliegenden Agglutinationsreihen ergaben im allgemeinen, da $\beta$ es gelingt, durch intravenöse Impfung von Kaninchen mit lebenden Kulturen Immunagglutinine gegen Soorpilze, wenn a uch nicht von hohem Titer, zu erzeugen, daß ferner mitdiesen Agglutininennichtnurder eigeneStamm, sonder $\mathbf{n}$ a uch andere Soorstämme reagieren, da $B$ aber a uch wieder $u$ nicht sämtliche Soorstämme durch sie erfaßt werden. Zu einem Urteil über die Spezifität der Reaktion berechtigten die angestellten Versuchsreihen kaum, da außer Soor- bzw. soorverdächtigen. Stämmen nur ein Saccharomycesstamm, Saccharomyces Leopold, der nicht agglutinierte - mitgeprüft wurde.

Als spezielles Ergebnis kann man den Agglutinationsreihen entnehmen, da $B$ die beiden vonder Patientingezüchteten Stäm me

*) Soorähnlicher Stamm, von der macerierten Haut einer an Mykosis fungoides erkrankten Pat. gezüchtet (s. unten). **) Der Sammlung der Klinik entnommen. 
Kopf und Daumen annähernd ebenso stark wie die eigenen Stämme mit den Sooragglutininen reagierten, und zwar beide ungefähr in gleichem Maße.

Komplementbindung.

Weiterhin wurde auch das eine der beiden Seren, das mit Stamm Hygienisehes Institut I hergestellt war, - 6 Tage nach der 4. Injektion entnommen - auf komplementbindende Antikörper gegenüber dem eigenen Stamm, dem Stamm Kopf und dem Stamm Hygienisches Institut II, den es nicht agglutiniert hatte, geprüft, weniger aus diagnostischen Gründen, als vielmehr um einen weiteren Beitrag zur Frage der Reaktionen zwischen Soorpilzen und Immunserum zu liefern, zumal da bisher über Komplementbindung bei Soor nur Erfahrungen am Menschen durch die Untersuchungen von Widal, Abrami usw. vorliegen*).

Als Extrakte wurden nach dem Vorgehen dieser Autoren A ufschwe mmun. gen von 24 stündigen Agarkulturen in 0,85 proz. Kochsalzlösung benutzt, und zwar wurden für ein Schrägagarröhrchen je nach der Dichte des Wachstums 3-4 $\mathrm{ccm}$ Flüssigkeit genommen. Von einer Filtration der Aufschwemmungen wurde abgesehen, da hierbei bei den mycelreichen Stämmen Hygienisches Institut I und II ein erheblicher Teil der Pilze - wie Proben ergaben - durch das Papierfilter zurückgehalten worden wäre. Statt dessen wurden die Aufschwemmungen längere Zeit intensiv geschüttelt.

$\mathrm{Zu}$ den Versuchen, die in Vierteldosen ausgeführt wurden, wurden konstante Serummengen $-0,25 \mathrm{~cm}$ der Verdünnung $1: 5-$ und fallende Antigenmengen $-0,25 \mathrm{~cm}$ der Verdünnungen $1: 4,1: 8$ und $1: 20$ - verwandt.

Außerdem wurden $z$ we i Normalkan inchenseren in der gleichen Weise angesetzt.

Das Immunserum lieferte mit sämtlichen Extrakten in allen Konzentrationen eine starke Komplementbindung, die nur mit dem Extrakt Hygienisches Institut II, dessen Pilze es nicht agglutiniert hatte, etwas schwächer war, während die beiden gleichzeitig angesetzten Normalseren mit denselben Extrakten nicht die geringste Hemmung ergaben, und, auch die üblichen Serum- und Extraktkontrollen, einwandfrei waren.

Mikrobicide Reagensglasversuche.

Schließlich wurden auch noch mit demselben Immunserum - gegen Stamm Hygienisches Institut I hergestellt und, 6 Tage nach der 4. intravenösen Injektion entnommen - und den Stämmen Hygienisches Institut I und Kopf einige mikrobicide Reagensglasversuche nach der von Neißer und Wechsberg ${ }^{30}$ ) für Bakterien angegebenen Technik vorgenommen:

1. Normalöse 24stündiger Agarkultur wurde in 100 oder, wo dichteres Wachstum vorhanden war, in $200 \mathrm{ccm}$ einer Mischung gleicher Teile Nährbouillon und

*) Fräulein M. Stern, Leiterin der serologischen Abteilung der Klinik, die die Güte hatte, die Reaktion auszuführen, sei auch an dieser Stelle ergebenster Dank ausgesprochen. 
0,85 proz. Kochsalzlösung aufgeschwemmt, und von dieser Aufschwemmung je 1/2 cem - d. h. 1/200 oder 1/400 Normalöse - in jedes Röhrchen gebracht.

Als Komplement diente frisches Meerschweinchenserum, von dem auf Grund ron Vorversuchen $1 / 2 \mathrm{ccm}$ einer Verdünnung 1:9 pro Röhrchen genommen wurde.

Das Immunserum wurde inaktiviert und in absteigenden Mengen hinzugefügt, der Inhalt aller Röhrchen durch Kochsalżösung auf 2 cem ergänzt.

Als Kontrollen wurden entsprechend den Vorschriften von Sachs und Ritz ${ }^{31}$ ) mitangesetzt: 2 Röhrchen mit Pilzen ohne Komplement und ohne Immunserum, von denen das eine am Anfang des Versuchs und das andere gleichzeitig mit den übrigen Röhrchen verarbeitet wurde, ein Röhrchen mit Komplement aber ohne Immunserum, eine Parallelreihe, die Immunserum und Pilze ohne Komplementzusatz enthielt, und eine weitere Parallelreihe, die statt des Immunserums Normalkaninchenserum enthielt.

Die Röhrchen wurden 3 Stunden bei $37^{\circ}$ gehalten und während dieser Zeit wiederholt durchgeschüttelt.

Danach wurden jedem Röhrchen $0,3 \mathrm{ccm}$ entnommen und mit 12,5 ccm Nähragar in gleich große Petrischalen ausgegossen, die für 24 Stunden in den Brutschrank kamen.

Gleichzeitig wurden auch die Röhrchen selbst weitere 24 Stunden im Brutschrank belassen Am nächsten Tage wurde die Beurteilung der Platten und Röhrchen vorgenommen.

Zunächst wurde ein Versuch mit hoher Immunserumkonzentration je $1 \mathrm{ccm}$ unverdünntes Serum, Verdünnung $1: 2,1: 4$ und $1: 8$ - und den Stämmen Hygienisches Institut, also dem eigenen Stamm, und Kopf angesetzt.

Mikrobicider Reagensglasversuch mit Stamm Hygienisches Tnstitut 1. Pilzaufschwemmung: 1 Normalöse in $100 \mathrm{ccm}$. Komplement $1: 9$. Technik s. oben.

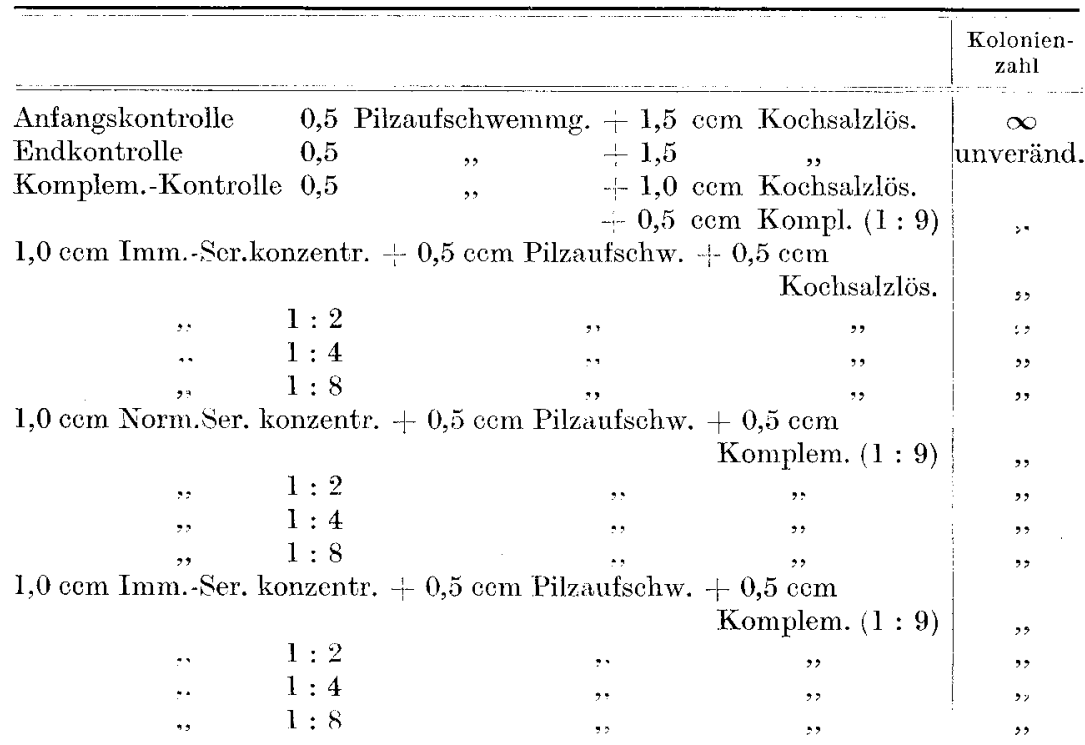


Das gleiche Resultat ergab der gleichzeitig mit Stamm Kopf (1 Normalöse in $200 \mathrm{ccm}$ ) angesetzte Versuch.

Die Versuche haben demnach ein negatives Ergebnis gezeitigt: Inaktiviertes Soorimmunserumvon starker Konzentration, durch frisches Meerschweinchenserum kompletiert, war innerhalb der Versuchszeit nicht imstande, die Zahl der lebenden Pilze zu vermindern.

Auch auf die Entwicklung dieser Pilze vermochte es einen hemmenden oder sonst schädigenden Einfluß nicht auszü̈ben, wie sich aus der Untersuchung der Versuchsröhrchen, nachdem sie weitere 24 Stunden im Brutschrank gestanden hatten, ergab:

In den Kontrollröhrchen, die die Pilze allein oder nur mit Komplement zusammen enthielten, hatten sich sehr zahlreiche kleine Klümpchen entwickelt, und genau das gleiche kräftige Wachstum war in den mit Normalserum angesetzten Reihen erfolgt.

Dagegen war in der Immunserumreihe die Zahl der Klümpchen wesentlich geringer als in den Kontrollen.

Aber das beruhte nicht etwa auf einer Fntwicklungshemmung durch das Immunserum. Denn das einzelne Klümpchen hatte sich hier sogar stärker ent. wickelt als im Normalserum.

Worauf die Verminderung der Klümpchenzahl beruhte, darüber gab die Kontrollreihe, die Immunserum ohne Komplement enthielt, Aufschluß. Auch hier war die Zahl der Klümpehen geringer bei gleichfalls stärkerem Umfang des einzelnen Klümpchens. Es handelte sich also um eine Eigenschaft des inaktiven Immunserums allein und nicht um eine Eigenschaft des Komplexes Immunserum. + Komplement, und man geht wohl mit der Annahme nicht fehl, die Erscheinung auf die im Immunserum erfolgte Aggl u ti nation zurückzuführen: Dadurch wurde die Zahl der Wachstumszentren und naturgemäß auch die Zahl der zur Entwicklung kommenden Klümpchen vermindert. Infolge dieser Verminderung der Zahl der Wachstumszentren wird gleichzeitig anch die stärkere Entwicklung des einzelnen Klümpchens zustande gekommen sein.

Auch von den Quellungserscheinungen, wie sie Roger and Noisette beschrieben haben, war an den Pilzen, die sich im Immunserum entwickelt hatten, nichts wahrzunehmen.

Somit besteht ein Unterschied zwischen den Befunden, die bei den vorliegenden Untersuchungen erhoben wurden, und denen von Roger sowie von Noisette, einen Gegensatz zu diesen Befunden braucht man aber nicht unbedingt darin zu sehen, da die Versuchsbedingungen in beiden Fällen verschieden waren. Dort waren die Pilze in reines, frisches Immunserum eingesät worden, hier dagegen in ein mindestens zur Hälfte verdünntes, inaktiviertes Immunserum, dem nur eine relativ geringe Kómplementmenge, dafür aber noch Nährbouillon zugefügt worden war.

Wenn man nun der Frage näher tritt, wodurch die Unterschiede in den Versuchsergebnissen bedingt sein können, so muß man zunächst feststellen, daß die Beobachtungen von Roger und Noisette nicht etwa auf unspezifische Vorgänge z. B. auf schlechte Wachstumsbedingungen im Serum, die in den vorliegenden Versuchen durch den Zusatz von Nährmitteln beseitigt wären, zurückzuführen sind, da die Autoren im normalen Vergleichsserum üppiges Wachstum gewöhnlicher Art beobachtet hatten. Aus demselben Grunde geht es nicht an, 
etwa den hohen Komplementgehalt des Serums an sich bezugsweise zusammen mit dem Gehalt an Normalambozeptoren dafür verantwortlich zu machen, sondern es hat sich nach ihren Angaben um eine Immunreaktion gehandelt.

Nur müßte dahingestellt bleiben, ob zu diesen Reaktionen der Immunantikörper allein genügte, oder Antikörper und Komplement zusammen erforderlich wären.

Dementsprechend brauchte der Unterschied zwischen den Befunden Rogers und Nois e t tes einerseits und den vorliegenden andererseits nur daravf zu beruhen, daß bei letzteren entweder die Konzentration an Immunserum, das allerdings bei dem höchstkonzentrierten Gemisch im Verhältnis $1: 2$ vorhanden gewesen war, oder an Komplement $b z w$. an beiden nicht ausreichte, um die Reaktion auszulösen.

Immerhin bleibt es bis zu einem gewissen (trade auffallend, daß Malvoz ${ }^{32}$ ), der mikrobicide Versuche, wenn auch nicht mit Soorpilzen so doch mit Hefen, angestellt hat, gleichfalls keine Spur einer mikrobiciden Wirkung tierischer Immunseren wahrzunehmen vermochte, weder Keimverminderung noch eine Entwicklungshemmung noch eine Formveränderung (Quellung), obwohl er ebenso wie Roger und Noisette konzentrierte frische Seren verwandte, die gleichfalls die zugehörigen Pilze zu agglutinieren imstande waren.

Man könnte gegen die vorliegende Versuchsanordnung noch einwenden, daß nur nach der für bactericide Versuche üblichen Einwirkungszeit von 3 Stunden Kulturen angelegt worden waren, und in Erwägung ziehen, ob sich nicht nach längerer Einwirkung eine mikrobicide Wirkung kulturell hätte nachweisen lassen. Indessen wäre darauf zu erwidern, daß sich doch die Beobachtung nicht nur auf diese Subkulturen, sondern a uch a uf die immunserumhaltigen Versuchsröhrchen selbst erstrekte, die noch weitere 24 Stunden bei Brutschranktemperatur belassen wurden, ohne eine schädigende Wirkung des Immunserums in Erscheinung zu bringen.

Es wurde noch in Betracht gezogen, ob nicht bei den vorliegenden Versuchen die Serumkonzentration zu hoch gewesen, sein und entsprechend den Beobachtungen bei hochkonzentrierten bactericiden Seren durch Komplementablenkung eine Keimabtötung verhindert haben konnte.

Aus diesem Grunde wurde das gewonnene Immunserum nochmals in höhcren Verdünnungen, die von 1:4 in geometrischer Progression, bis 1 : 1280 reichten, bei gleicher Versuchsanordnung dem eigenen Stamm und dem Patientenstamm Kopf gegenüber geprüft - wieder u m mit demselben negativen Resultat.

Demnach hat sich bei der angewandten Versuchstechnik im Antisoorserum eine mikrobicide Wirkung nicht nachweisen lassen.

Im ganzen ergab sich also als Resultat der serologischen Untersuchungen, daB durch intravenöse Impfung von Kaninchen mit lebenden Soorpilzen Immunseren gewonnen wurden, die agglutinierende und komplementbindende Antikörpergegen Soorpilze enthielten, in denen aber mikrobicide Antikörper nicht gefunden werden kor nten.

Diese Immunseren übten die gleiche Wirkung wie gegen- 
über dem eigenen Stamm auch den Patientenstämmen Kopf und Daumen gegenüber aus.

$\mathrm{Ob}$ dieser Befund für sich allein eine Einordnung jener Pilze in die Soorgruppe gestatten würde, hängt von der Frage ab, wie weit Immunreaktionen bei Soorpilzen spezifisch sind.

Mit dem geringen Untersuchungsmaterial, das über die Immunreaktionen bei Soor vorliegt, läßt sich diese Frage nicht mit Sicherheit entscheiden.

Widal, Abrami usw. haben gefunden, daß die Seren soorkranker Menschen Gruppenreaktionen mit Sporotrichon- und Aktinomycespilzen gaben, ebenso umgekehrt Sporotrichose- und Aktinomykoseseren mit Soorpilzen, und haben, was für die vorliegende Frage einer Differenzierung zwischen Soorpilzen und anderen Blastomyceten von besonderer Bedeutung ist, weiterhin festgestellt, daß die Seren ihrer Soorkranken meist a uch mit Sace haro m y ceten Komplementbindung gaben, während sie über Agglutination mit Saccharomyceten keine Angaben gemacht haben.

Darüber, ob diese Verhältnisse auch für künstlich erzeugte Immunseren tierischer Herkunft. Geltung haben, liegen Feststellungen bisher nicht vor, und auch, wenn man die Beobachtungen an Hefe pilze $n$ hier zur Orientierung heranziehen wollte, kommt man zu keiner bestimmten Vorstellung, da auch auf diesem Gebiet noch keine ausreichende Klärung erfolgt ist: teils wurden Gruppenreaktionen festgestellt, teils aber auch eine gewisse Abgrenzbarkeit - wenn auch teilweise nur quantitativer Natur - einzelner Arten. (Malvoz, Sehütze ${ }^{33}$ ).

Auch die vorliegenden Versuche, deren Hauptzweck schließlich nur in einer Einordnung der gefundenen Pilze in das System bestand, bringen keine genügende Klärung dieser Frage. Immerhin hat ein zur Untersuchung herangezogener Saccharomyces (S. Leopold) keine Agglutination mit Soor ergeben, und hat sich sogar a uch ein Teil der untersuchten Soorpilze - wenigstens durch Agglutination - abgrenzen lassen, ein Befund, der auch dem von Noisette erhobenen entsprach.

Überblickt man nunmehr die Ergebnisse der kulturellen, mikroskopischen, tierexperimentellen und, serologischen Untersuchungen, so erscheint der Schluß berechtigt, $d$ a $\beta$ die a us den verschiedenen Kör pergegenden der Patientin gezüchteten Pilze identisch waren, und daß sie der Soorgruppe angehörten. Wenn auch die einzelnen Untersuchungsergebnisse, für sich allein betrachtet, $\mathrm{zu}$ dieser Schlußfolgerung nicht ausreichen würden, so liefern sie doch in ihrer Gesamtheit das Bild, das auch die aus typischen Soorplaques gezüchteten Pilze bieten.

De Beurmann und Gougerot ${ }^{34}$ ), die sjch mit der Systematik der Soorpilze und pathogenen Hefen beschäftigt haben und diese gemeinsam mit den Oidiomyceten (Zymonemen), den Erregern der Gilchristschen Krankheit, unter die Exoaskeen und den Soorpilz im speziellen nach $\mathrm{V}$ uille min unter die Endomyceten (Endomyces albicans) eingereiht wissen wollen, haben von den Endomyceten noch die Parendomyceten abgetrennt. 
Sie bringen dort diejenigen soorähnlichen Pilze unter, die teils noch nicht genügend exforscht sind, um sie zu den Endomyceten zu zählen, teils geringe $\mathbf{A b}$ weichungen von ihnen zeigen.

Ohne über die Berechtigung dieser Gruppierung im allgemeinen ein Urteil abgeben zu wollen, das auch mehr dem Botaniker zustehen würde, soll nur betont werden, daß nach den vorliegenden Untersuchungsergebnissen, die gefundenen Pilze nicht diesen Parendomyceten sondern den Endomyceten zuzurechnen wären.

Demnach würde sich die beobachtete Nagelerkrankung folgendermaßen charakterisieren lassen:

Bei einer an Salvarsan-Dermatitis leidenden Patientin hatten sich Soorpilze auf macerierten, der Kopfhaut auflagernden Epidermismassen saprophytisch angesiedelt. Wahrscheinlich waren sic von dort aus durch Berührung auf die keratotisch veränderten Nägel der Patientin übertragen worden und hatten hier eine Mykose hervorgerufen.

Uber reinsaprophytisches Wachstum soorähnlicher Pilze a uf der menschlichen Haut, wie es im vorliegenden Falle auf der erkrankten Kopfhaut zur Beobachtung kam, ist trotz der Wichtigkeit. dieser Frage für die Beurteilung der ätiologischen Bedeutung derartiger Pilze bei Hauterkrankungen (s. oben) nur wenig bekannt (s. Fischl.), zum erheblichen Teil wohl wogen der Schwierigkeiten, die es bereitet, unter den hefeähnlichen Pilzen, die man in zahlreichen Fällen auf der normalen oder pathologisch veränderten Haut festgestellt hat (s. Zusammenstellung von Marzinowski und Bogrow ${ }^{35}$ ), die Angehörigen der Soorgruppe herauszufinden.

Um einen klcinen Beitrag zu dieser Frage zu licfern, wurde im Anschluß an die vorliegende Beobachtung noch bei einigen anderen Patienten, diogleichfalls an nässenden Hauterkrankungen litten, nach ähnlichen Pilzen gesucht.

Hierbei erwies sich die Züchtung auf Sabouraudschem Maltoseagar -- ergänzt durch mikroskopische Untersuchung des Ausgangsmaterials im Kalilaugeund Grampräparat - wegen des elektiven Verhaltens dieses Nährbodens auch den Soorpilzen gegenüber als besonders geeignet.

Zur Untersuchung kamen 3 Fälle von generalisierter Dermatitis nach kombinierter antiluetischer Kur (2 Frauen, I Mann), ein chronisches Fkzem (Mann), eine sekundäre Lues mit nässenden Papeln am After und Nabel (Mann) und eine Mycosis fungoides mit prämykotischer Erythrodermie (Frau). Bei 3 dieser Patienten wurden auf der Oberflächeder Haut soorähnliche Pilze gefunden, und zwar bei den beiden weiblichen Kranken mit generalisierter Dermatitis, bei denen Hyperkeratosen und bei einer auch Melanodermie auf eine Beteiligung des Salvarsans am Krankheitsprozeß hinwiesen, sowie bei der an Mycosis fungoides leidenden, gleichfalls mit Arsen behandelten Kranken.

Wenn man noch hinzunimmt, daß auch die mykotische Nagel- 
erkrankung eine Frau mit salvarsangeschädigter Haut betroffen hatte, so könnte man geneigt sein, an besondere Beziehungen zwischen weiblichem Geschlecht sowie Arsen einerseits und Soorpilzen andererseits $\mathrm{z} u$ denken.

Indessen muß darauf hingewiesen werden, daß man nach dem vorliegenden Material noch nicht berechtigt ist, einen weitreichenden Schluß in dieser Richtung zu ziehen, da erstens die Gesamtzahl der untersuchten Fälle dazu zu gering war, und zweitens auch bei der Auswahl der Fälle die beiden möglicherweise dispositionschaffenden Momente zahlenmäßig stark begünstigt worden waren.

Die Verteilung der Pilze über den Körper war derart, daß sie auf Hautbezirken von normalem Aussehen zu fehlen schienen, die macerierten Gebiete bevorzugten, sich aber auch auf nässenden Hautstellen ohne Macerationserscheinungen fanden. In einem Fall konnten sie auch in keratotischen unter dem freien Nagelrand liegenden Massen nachgewiesen werden, hatten sich hier aber nur an der Oberfläche und nicht im Gewebe selbst angesiedelt. Bei zwei unter diesen drei Fällen wurden die Pilze gleichzeitig auch a uf der Schleimhaut, das eine Mal auf der Mundscbleimhaut, das andere Mal auf Mund- und Scheidenschleimhaut, gefunden, ohne hier soorartige Veränderungen hervorgerufen zu haben.

In allen drei Fällen zeigten die gefundenen Pilze in ihrem biologischen Verhalten eine erhebliche Übereinstimmung mit echten Soorpilzen, bzw. mit den Pilzen, wie sie bei der Nagelerkrankung gefunden worden waren. Nur wurden ihre Eigenschaften nicht so weit in alle Einzelheiten*) verfolgt, daß man sie nach den Untersuchungsergebnissen mit diesen Pilzen zu identifizieren berechtigt wäre; immerhin reichten die Befunde aus, um sie als soorähnlich anzusprechen.

Übereinstimmend bildeten sie in Gelatinestichkulturen nach 8 Tagen zahlreiche fädige Ausläufer, töteten Mäuse nach intravenöser Einverleibung einer $1 / 5$ Normalöse 24 stündiger Agarkultur in 18-24 Stunden, riefen bei Meerschweinchen in Dosen von $1 / 2$ Normalöse bei subkutaner Verabfolgung nichtperforierende Abseesse ohne Allgemeininfektion und bei peritonsaler Impfung überhaupt keine sichtbaren Krankheitserscheinungen hervor.

Sie zersetzten übereinstimmend Dextrose, Lävulose und Maltose unter Gasbildung, dagegen im allgemeinen nicht Saccharose, Laktose und Galaktose; nur bei einem Stamm waren Spuren einer Gasbildung nach 4tägigem Wachstum bei $37^{\circ}$ in saccharosehaltiger Nährbouillon festzustellen.

Dagegen verhielten sich die Pilze bei der mikroskopischen Untersuchung. des zur Kultur benutzten Ausgangsmaterials insofern verschieden, a]s in $2 \mathrm{~F}$ ällen neben zahlreichen Hefeformen auch ganz vereinzelt Mycelien, in dem 3. Fall aber nur Hefeformen nachgewiesen wurden.

Spricht das Auftreten von Mycelien für die Zugehörigkeit der. Pilze zur Soorgruppe, so spricht das Fehlen derselben doch nicht dagegen, da auch bei typischen

*) Die Agglutinationsprobe wurde nur bei einem dieser Stämme (Mykosis fungoides), und zwar mit negativem Erfolge, ausgeführt. 
Sooraffektionen der Mundschleimhaut in einer erheblichen Zahl der Fälle Mycelformen nicht aufzufinden sind (Noisette sowie Stoos, zit. nach Noisette). Außerdem waren bei allen 3 Stämmen im Tierexperiment - in subcutanen Abscessen 2 Tage nach der Impfung - Mycelfäden, und zwar im Übergewicht gegenüber den Hefeformen, nachzuweisen, obwohl in dem von Schrägagarkulturen stammenden Impfmaterial die Mycelformen, die hauptsächlich in flüssigen Nährböden in Erscheinung traten, fast vollständig gefehlt hatten.

Nach diesen Befunden bekommt man den Eindruck, daß soorähnliche Pilze nicht selten als Saprophyten bei Entzündungen der Haut, besonders wo Neigung zur Exsudation und vor allem zur Maceration vorhanden ist, vorzukommen scheinen, und daß es infolgedessen eingehendster Untersuchungen bedarf, bevor man diesen Pilzen einen ätiologischen Anteil an Krankheitsprozessen von ähnlichem Aussehen einräumt.

\section{Literatur.}

1) Ibrahim, Arch. f. Kinderheilk. 55, 91. 1911. - 2) Beck, Dermatol. Studien. (Festschrift f. Unna.) 20, 494. 1910 n. Budap. Orv. Ujsag 1913, Nr. 13 (ref. Dermatol. Wochenschr. 60, 301. 1915.) - ${ }^{3}$ ) Ka uf mann-Wolf, Dermatol. Zeitschr. 22, 441. 1915. - $\left.{ }^{4}\right)$ Ja k obi, dieses Archiv 84, 289. 1907. - ${ }^{5}$ ) Küs ter, Arch. f. Hyg. 62, 365. 1907. - ${ }^{6}$ ) Gougerot und Gancéa, Bull. de la Soc. franc. de Derm. et Syphil. 1914-15, Nr. 7, S. 335. - $\left.{ }^{7}\right) \mathrm{H}$ u délo und Montla ur ,Bull. de la Soe. frane. de Derm. et Syphil. 1914/15, Nr. 7, S. 403. - ${ }^{8}$ ) Muijs, Dermatol. Wochenschr. 64, 65. $1918-{ }^{9}$ ) Forbes, Brit. journal of dermatol. 21, 221. 1909. $\left.-{ }^{10}\right)$ Pellier, Ann. de dermatol. et de syphiligr. 1912, S. 563. - $\left.{ }^{11}\right) \mathrm{Kum} \mathrm{mer}$, Dermatol. Wochenschr. ro, 109. 1920. Sitzungsber. d. Wien. Dermatol. Ges. v. 4. XII. 1919. - 12) Dübendorfer, Dermatol. Centralbl. 7, 290. 1904. 13) Selenew, Ikonograph. dermatol. 3, 'Tab. 23-25. 1906. - ${ }^{14}$ ) Bourgeois, Dermatol. Zeitschr. 22, 411. 1915. - 15) Heller, Die Krankheiten der Nägel. Berlin. 1900. - ${ }^{16}$ ) Sabouraud, Ann. de dermatol. et de syphiligr. 1900, S. 457. - ${ }^{17}$ Widal, Abrami, Joltrain, Brissaud, und Weill, Ann. de l'inst. Pasteur, 24, 1. 1910. - 18) Leuchs und Schöne, Zeitschr. f. Hyg. 60, 149. 1908. - $\left.{ }^{19}\right)$ Pla ut, Die Hyphenpilze oder Eumyceten. Handb. d. pathog. Mikroorg. 2. Aufl. 5, 42. 1913. - 20) Buschke, Die Sproßpilze. Ebenda S. 155. -.. 21) Fischl, Ergeb. d. inn. Med. u. Kinderheilk. 16, 107. 1919. - ${ }^{22}$ ) Quantz, Zeitschr. f. Hyg. 78, 193. 1914. - ${ }^{23}$ ) Grasset, Etudes sur le Muguet. Thèse de Paris. 1894. - 24) Noissette, Recherches sur le champignon de Muguet. Thèse de Paris. 1898. - ${ }^{25}$ ) Fischer und Brebeck, Zur Morphologie, Biologie und Systematik der Kahmpilze, der Monilia candida Hansen und des Soorerregers. Jena. Fischer. 1894. - ${ }^{26}$ ) Linossier und Roux, Compt. rend. de l'Acad. des Se. 109, 752. 1889. - ${ }^{27}$ ) Vuillem in, Ebenda. 127, 630. 1898. - ${ }^{28}$ ) Heim, Lehrb. d. Bakteriologie, 5. Aufl. Stuttgart. 1918. - $\left.{ }^{29}\right)$ Roger, Compt. rend. de la soc. de biol. Serie 10, 3, 728, 1896. - ${ }^{30}$ ) Neisser und Wechs berg, Münch. med. Woehenschr. 1901, Nr. 18. - ${ }^{31}$ ) Sachs und Ritz, Handb. d. pathog. Mikroorg., 2. Aufl. Jena. 1913. Bd. 3, S. 52. - ${ }^{32}$ ) Malvoz, Centralbl. f. Bakt. u. Parasitenk. 29, 688. 1901. - ${ }^{33}$ ) Schütze, Zeitsehr. f. Immunitätsforsch. Orig.Bd. 8, 611. 1911. - 31) De Beurmann und Gougerot, La Tribune Médicale v. 7.-14. Aug. 1909. - ${ }^{35}$ ) Marzinows ki und Bogrow, dieses Archiv 86, 215. 1907. 